[Frontiers in Bioscience E2, 293-311, January 1, 2010]

\title{
Response of the thermoregulatory system to toxic insults
}

\section{Christopher J. Gordon}

Toxicology Assessment Division, Neurotoxicology Branch,National Health Effects and Environmental Research Laboratory, U.S. Environmental Protection Agency, Research Triangle Park, North Carolina 27711

\section{TABLE OF CONTENTS}

1. Abstract

2. Introduction

3. Thermoregulatory profile

4. Impact of environmental temperature on toxic response

4.1. Ideal ambient temperature to study thermoeffector function

4.2. Temperature and biological dose of a toxicant

4.3. Magnitude and duration of a toxicological response

5. Acute thermoregulatory responses to toxicants

5.1. Forced and regulated changes in temperature

5.2. Is toxicant induced hypothermia forced or regulated?

5.3. Importance of behavioral thermoregulation

5.4. Mechanism of action

5.5. Recommended approach to study thermoregulatory effects of toxicants

6. Thermoregulatory effects of alcohol

7. Toxic chemicals eliciting hyperthermia

8. Advantages of a hypothermic response

9. Delayed and chronic effects

10. Scaling thermoregulatory responses to toxic agents

11. Acknowledgements

12. References

\section{ABSTRACT}

The physiological response to environmental toxicants and drugs is modulated by the thermoregulatory system. Environmental and body temperature can affect the entry of toxicants into the body through pulmonary, cutaneous, and gastrointestinal routes. Thermoregulation can ultimately influence the metabolic clearance of chemicals and their toxicity, including lethality. The thermoregulatory response following acute exposure to many toxic chemicals involves a regulated hypothermic response, characterized by activation of autonomic thermoeffectors to raise heat loss and a behavioral preference for cooler temperatures. Moderate hypothermia in rodents improves recovery and survival following toxic exposure. In relatively large mammals, including humans, the hypothermic response is minimal. Fever-like responses are often seen in humans and other large mammals exposed to many toxicants. Fever is also observed in rodents exposed to some toxicants provided that core temperature can be monitored without disturbing the animal (e.g., telemetry). Overall, the universal effects of temperature on chemical toxicity call for researchers to have a better understanding of how body and ambient temperature affect the physiological response to environmental toxicants.

\section{INTRODUCTION}

Why should temperature be considered as a significant factor in toxicological studies? First, while body temperature of the majority of mammals is normally stable over a wide range of ambient temperatures, altered thermoregulation is seen upon exposure to toxicants, with the effects usually being more pronounced in rodents and other small mammals. Second, large mammals such as humans are able to maintain a stable core temperature following toxicant exposure but environmental heat and cold stress will nonetheless exacerbate their physiological and behavioral responses to a toxicant. Third, by virtue of the stable nature of body temperature, any environmental perturbation or insult that changes temperature should be considered as a biologically significant event. One should look at temperature regulation as a hallmark of homeostasis and consider any change in core temperature to be biologically significant. To this end, one can use body temperature as a benchmark of toxicological exposure because a temperature change indicates a significant change in physiological homeostasis (1). The purpose of this paper is to provide a review of the impact of environmental and body temperature on the integrative thermoregulatory response to toxic insults. 


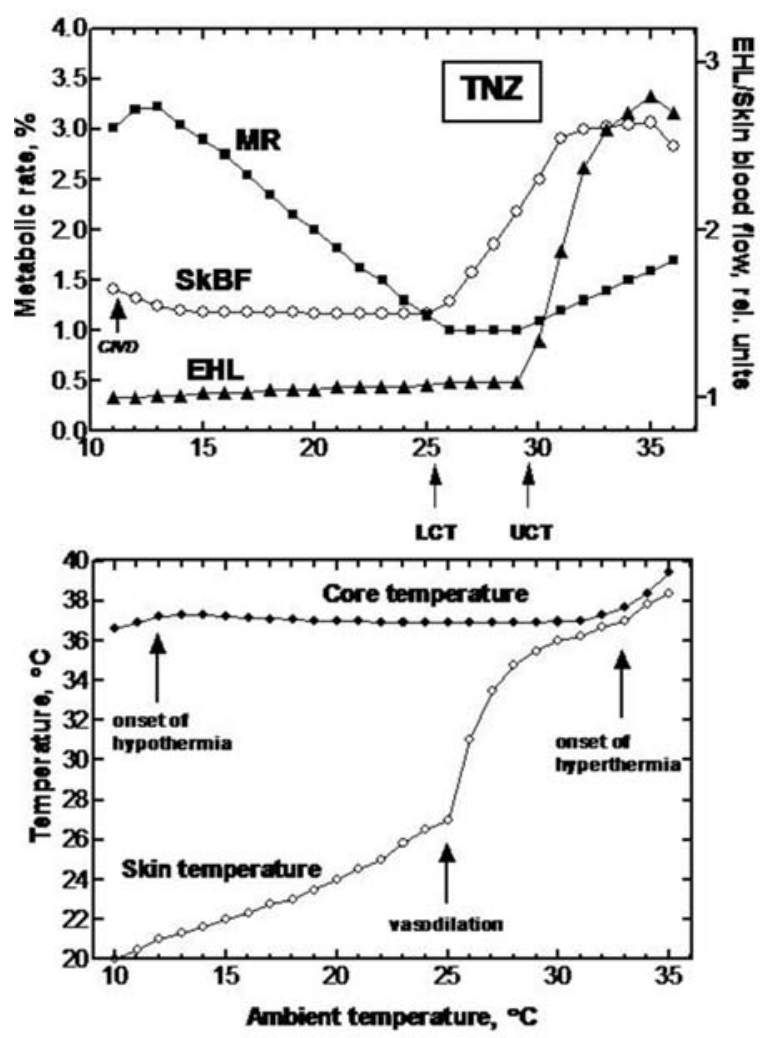

Figure 1. Generalized patterns of core and skin temperature and activity of autonomic thermoeffectors as a function of ambient temperature in a homeotherm. SkBFskin blood flow, EHL-evaporative heat loss; MR-metabolic rate; LCT-lower critical temperature; UCT-upper critical temperature, TNZ-thermoneutral zone.

\section{THERMOREGULATORY PROFILE}

The toxicity of drugs and chemical toxicants is commonly evaluated in rats and mice. As will be discussed later, the thermal sensitivity of rodents is attributed primarily to their small size. Understanding the thermoregulatory profile is critical for the study of toxicants on body temperature (Figure 1). A thermoregulatory profile such as the theoretical responses depicted in Figure 1 is an assessment of the effects of environmental temperature on the core and skin temperatures, and activity of autonomic thermoeffectors. There is a range of ambient temperatures termed the thermoneutral zone, where metabolic rate is equal to or near basal levels. In this zone of ambient temperatures, temperature regulation is achieved by control of sensible heat loss without regulatory changes in metabolic rate or evaporative water loss. The control of body temperature in the thermoneutral zone is achieved with modulation in skin blood flow which controls the rate of heat loss with no additional metabolic requirements. As ambient temperature decreases below the thermoneutral zone, blood flow to the skin is minimized as a result of peripheral vasoconstriction. With further reduction in ambient temperature, heat production must increase above basal levels by shivering and non-shivering thermogenesis to match heat loss to the environment. If this did not occur, hypothermia would ensue. The ambient temperature where metabolic rate increases is termed the lower critical temperature. As ambient temperature decreases below the lower critical temperature, skin temperature falls passively but may increase with extreme cold exposure as a result of cold induced vasodilation (CIVD) of the peripheral blood vessels. This is a protective response to keep exposed tissues from freezing. An ambient temperature is eventually reached where metabolic rate cannot compensate for the heat loss and the core temperature decreases, leading eventually to hypothermic death.

As ambient temperature increases above the thermoneutral zone, skin blood flow increases and there is a rise in skin temperature. However, if skin blood flow is maximal, skin temperature cannot increase above the internal core temperature. This means that as the ambient temperature approaches the level of core temperature, the gradient between the skin and ambient temperature becomes smaller, thus limiting the rate of heat loss by convection, conduction, and radiation. Hence, at temperatures above the thermoneutral zone, evaporative heat loss mechanisms (i.e., panting, sweating, saliva grooming) must be activated to maintain thermal balance. This ambient temperature is termed the upper critical temperature. It is also identified with the point where core temperature and metabolism begin to rise (see 2). At around the point of the upper critical temperature, skin temperature has increased to a level that is just below core temperature, reflecting maximal redistribution of warm blood from core to the periphery. With further increase in ambient temperature, skin and core temperature parallel each other until the point of thermoregulatory failure. At this point, evaporation is ineffective to maintain sufficient heat loss and core temperature spirals upward leading eventually to hyperthermic death.

Researchers with little understanding of thermoregulation may consider rats and mice to be poor thermoregulators. This is a misconception because mice and rats are quite capable of defending a relatively constant body temperature over a wide range of ambient temperatures (for review, see 3). For example, male and female rats housed individually in cages with wire-screen floors are able to maintain tightly regulated core temperature during the day and night over a wide range of ambient temperatures (Figure 2). Thermal homeostasis is achieved through the selective activation of thermoeffectors to increase heat production and heat loss mechanisms upon exposure to warm temperatures. Female rats are smaller but are able to maintain as stable a core temperature in the cold as do male rats. Smaller females are better able to maintain core temperature when exposed to warmer ambient temperatures. When these effector responses are hampered by experimental manipulation (e.g., restraint) or by treatment with a drug or chemical that specifically targets one or more of the effector systems, then one will see marked changes in the rodent's body temperature. If the physical characteristics of the housing system affects heat production or heat loss, the thermoeffector function may be 
Table 1. Hyperthermic $(\uparrow)$ and hypothermic effects $(\downarrow)$ of a toxicant or drug that stimulates or blocks thermoeffectors at cool, thermoneutral, or warm ambient temperature. Number of arrows indicates relative magnitude of change in core temperature

\begin{tabular}{|c|c|c|c|c|c|c|}
\hline & $\begin{array}{l}\text { Thermogenesis } \\
\text { increased }\end{array}$ & $\begin{array}{l}\text { Skin blood flow } \\
\text { increased }\end{array}$ & $\begin{array}{l}\text { Evaporation } \\
\text { increased }\end{array}$ & $\begin{array}{l}\text { Thermogenesis } \\
\text { blocked }\end{array}$ & $\begin{array}{l}\begin{array}{l}\text { Skin blood flow } \\
\text { blocked }\end{array} \\
\end{array}$ & $\begin{array}{l}\begin{array}{l}\text { Evaporation } \\
\text { blocked }\end{array} \\
\end{array}$ \\
\hline Cool temperature & $\uparrow$ & $\downarrow \downarrow$ & $\downarrow$ & $\downarrow \downarrow \downarrow \downarrow$ & & \\
\hline $\begin{array}{l}\text { Thermoneutral } \\
\text { temperature }\end{array}$ & 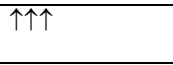 & $\downarrow$ & & $\downarrow \downarrow$ & 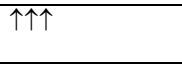 & $\uparrow$ \\
\hline Warm temperature & 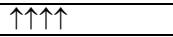 & & & $\downarrow$ & 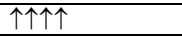 & 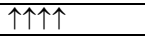 \\
\hline
\end{tabular}

Reproduced with permission from From Gordon (1).

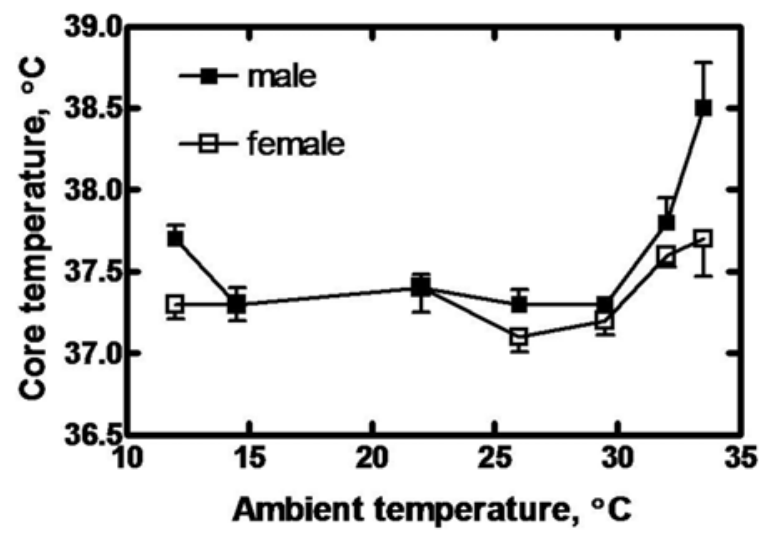

Figure 2. Effect of housing at ambient temperatures of 12 to $33{ }^{\circ} \mathrm{C}$ on the core temperature of male and female LongEvans rats housed for 24 hours on a wire-screen floor with food and water provided ad lib without bedding material. From Yang and Gordon (64).

overtaxed leading to possible deviations in core temperature.

\section{IMPACT OF ENVIRONMENTAL TEMPERATURE ON TOXIC RESPONSE}

Whether a toxicant will induce hypothermia, hyperthermia, or have no effect on body temperature will depend largely on the thermal environment (i.e., combined effects of air temperature, relative humidity, solar radiation, wind speed, and insulative quality of the cage and bedding material) and the sensitivity of the animal's thermoregulatory system to the toxic agent (Table 1). The thermal environment should always be considered in a drug/toxic study even if thermoregulation is not a primary endpoint. Since a change in body temperature can affect a multitude of physiological processes, a drug or toxicant can indirectly affect a non-thermoregulatory endpoint.

The potential for body temperature to change, indicated by the number of arrows in each block of in Table 1 , is generally dependent on whether the animal is housed in a cool, warm, or thermoneutral environment. For example, a drug that blocks metabolic thermogenesis will manifest the most effective change in body temperature when exposure occurs at a relatively cool ambient temperature. A toxicant that induces peripheral vasoconstriction, thus restricting blood flow and heat loss from the skin, will have relatively minor effects in a cold environment because the animal is in a state of peripheral vasoconstriction; however, the same chemical would lead to hyperthermia in a thermoneutral and warm environment. On the other hand, an agent that causes peripheral vasodilation would be mostly ineffective in a warm environment because skin blood flow is already elevated and an additional vasodilatory action should have little effect on total heat loss. Blocking salivation in rodents or sweating in humans would have little effect in the cold but would lead to dramatic hyperthermia if the blocking agents are administered in a warm environment.

If the toxicant impairs one thermoeffector without affecting CNS thermoregulatory control, then one would expect the animal to utilize other thermoeffectors to maintain thermal homeostasis. For example, given a scenario where skin blood flow was elevated in a cold environment, then metabolic thermogenesis could theoretically increase to counter the increased heat loss. Stimulation of heat production in a warm environment, such as occurs by exposure to chemical agents that uncouple oxidative phosphorylation, should be accompanied by a marked increase in evaporation (4). Overall, these are idealized situations, and drugs and toxicants generally affect the function of more than one thermoeffector system.

\subsection{Ideal ambient temperature to study thermoeffector function}

The relationship in Table 1 summarizes how ambient temperature interacts with the thermal efficacy of a drug or toxicant. Related to this issue is how one selects appropriate ambient temperatures to study a thermoeffector response to a toxicant. This can be very important in the study of forced and regulated changes in body temperature as is discussed in Section 6.0. In theoretical plots of shivering and skin blood flow as a function of ambient temperature, there are crucial zones of ambient temperature that must be selected if one wants to study how a thermoeffector is activated or suppressed (Figure 3). For example, if a toxicant is suspected of eliciting peripheral vasodilation then the animal should be maintained at an ambient temperature just below the threshold temperature for vasodilation. In this way there is adequate room for the thermoeffector response to be initiated without compromising the control of core temperature. If the temperature is well below this point then vasodilation may not be initiated because cold temperatures suppress the vasodilatory response of the chemical agent. On the other hand, if ambient temperature is well above the threshold for vasodilation, a toxicant-induced vasodilation would be difficult to observe. To assess a vasoconstrictive response, the subject needs to be maintained at a temperature above the threshold for vasodilation. Peripheral vasomotor control 


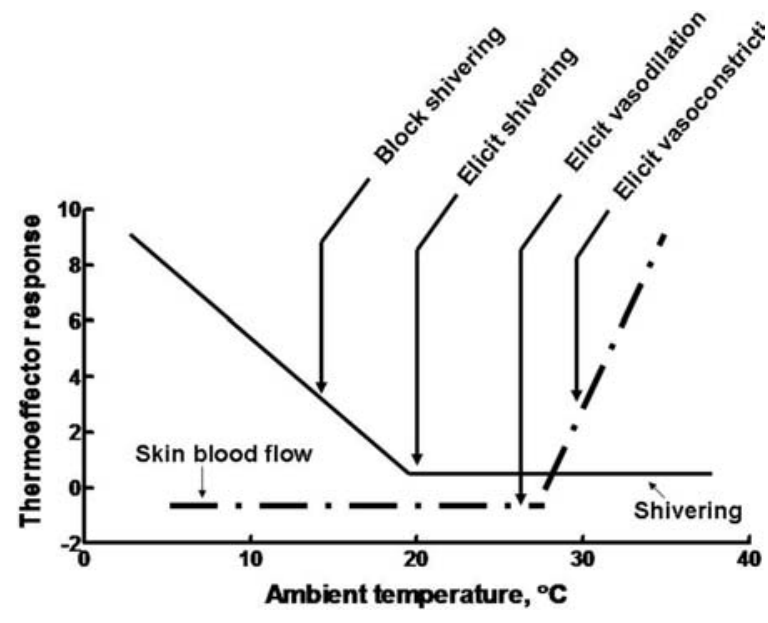

Figure 3. Selecting the appropriate ambient temperatures to study how a toxicant or drug modulates a thermoeffector. Theoretical curves showing effects of ambient temperature on shivering thermogenesis and peripheral vasomotor tone are plotted along with the ambient temperatures one would use to activate or suppress these thermoeffectors.

of tail blood flow is essentially an on-off control mechanism of arterial blood flow to the tail. Below a crucial ambient temperature of $26-28{ }^{\circ} \mathrm{C}$, blood flow is constricted and it cannot be further constricted with any additional neural or hormonal influence. Hence, to develop an assay for vasoconstrictive agent, the ambient temperature has to be above the species' threshold temperature for vasodilation. Moreover, there is no single ambient temperature that can be used to assess if a drug or toxicant induces peripheral vasoconstriction or vasodilation.

The same can apply to study agents that stimulate or suppress shivering (Figure 3 ). To block shivering the animal needs to be in a relatively cold environment where shivering is active. But if the temperature is too cold then the toxic agent would cause marked hypothermia with possible undesirable side effects. Activation of shivering should again be carried out at an ambient temperature just above the threshold temperature for shivering. These same principles can be applied to other thermoeffectors such as evaporation and behavioral thermoregulation.

\subsection{Temperature and biological dose of a toxicant}

The pharmacokinetics (i.e., time course and clearance) and pharmacodynamic (i.e., physiological effects) of drugs and toxicants are influenced by temperature. The effects of temperature on the pharmacokinetics of a chemical can be as simple as the direct effects of temperature on the activity of an enzyme that metabolizes the toxicant, or complex, such as heat stress-induced sweating that increases the cutaneous absorption of a toxicant through the skin. When studying the role of temperature on pharmacokinetics, thermal sensitivity is commonly expressed in terms of either the $\mathrm{Q}_{10}$ or the temperature coefficient. $\mathrm{Q}_{10}$ is defined as "the ratio of the rate of a physiological process at a particular temperature to the rate at a temperature $10{ }^{\circ} \mathrm{C}$ lower, when the logarithm of the rate is an approximately linear function of temperature" and is calculated by the following equation (2):

$\mathrm{Q}_{10}=\left(\mathrm{R}_{2} / \mathrm{R}_{1}\right)^{10 /(\mathrm{T} 2-\mathrm{T} 1)} \quad$ Equation 1

Where $R_{1}=$ rate of activity at one temperature, $T_{1}$; and $R_{2}=$ rate of activity at another temperature, $T_{2}$. Thus, a $Q_{10}$ of 2 means that the activity doubles with each $10{ }^{\circ} \mathrm{C}$ elevation in temperature, a $\mathrm{Q}_{10}$ of 3 is tripling of activity, and so on. A $Q_{10}$ of 1 means there is no change in activity with temperature and a $\mathrm{Q}_{10}$ of less than 1 means that activity increases with a reduction in temperature. $\mathrm{Q}_{10}$ typically ranges between 2 to 3 for most biological processes. $\mathrm{Q}_{10}$ varies with temperature, usually decreasing in magnitude with a progressive rise in temperature. Hence, it is essential to report the temperature range of its determination when reporting $\mathrm{Q}_{10}$ values (5).

Temperature coefficient is also a commonly used parameter to describe thermal sensitivity and interaction with drugs and toxicants and is defined as "the ratio between the change in any temperature dependant activity and the defined temperature range within which this change occurs" (2). Temperature coefficient is an expression of the change in activity of a process for a $1.0{ }^{\circ} \mathrm{C}$ change in temperature. Unlike the $\mathrm{Q}_{10}$ parameter, the temperature coefficient is either positive or negative, depending on how temperature affects the physiological process. Temperature coefficients are probably used more often than the $\mathrm{Q}_{10}$ in studies on the effect of temperature on toxicological and pharmacological processes in birds and mammals. Like $\mathrm{Q}_{10}$, temperature coefficient will also be dependent on the temperature range used in its calculation.

Physiologically based pharmacokinetic (PBPK) models may incorporate temperature coefficients into every relevant organ, tissue, or compartment because metabolic activation, deactivation, and clearance of a toxicant will be affected directly by body temperature (Figure 4). These models are essential in toxicology and are used to predict the disposition and fate of a chemical in various tissue or organ compartments. However, in addition to core temperature, there are other aspects of the thermoregulatory system that must be factored into PBPK models, including temperature acclimation and exercise $(1,6)$.

A basic PBPK model with a simple thermoregulatory model is presented in Figure 4 to show how the routes of entry of toxicants into the body can interact with the thermoregulatory system. Specific examples are discussed later. Other than the skin, all of the organ systems of the model are essentially immersed in the thermal core and blood flow to each of these systems is generally unaffected by the external environment provided that core temperature is regulated. Many toxicants are metabolized in the liver and/or cleared through the kidneys. The efficacy of these systems will be impaired by changes in core temperature. Skin absorption of toxicants, such as organophosphate insecticides, is affected by skin temperature and sweating (7). The thermoeffectors for vasomotor control and sweating are affected by ambient 


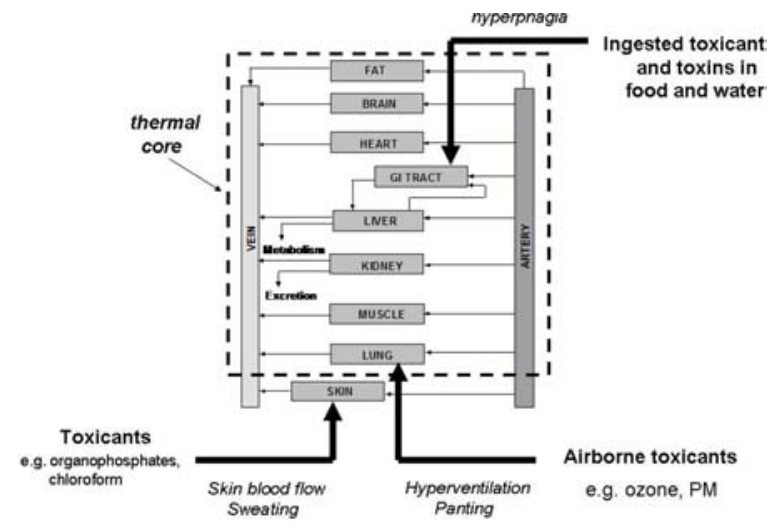

Figure 4. Incorporation of a basic pharmacokinetic/pharmacodynamic model and thermoregulatory model to demonstrate how core, peripheral, and ambient thermal environment influence the kinetics and dynamics of toxicants (see 1).

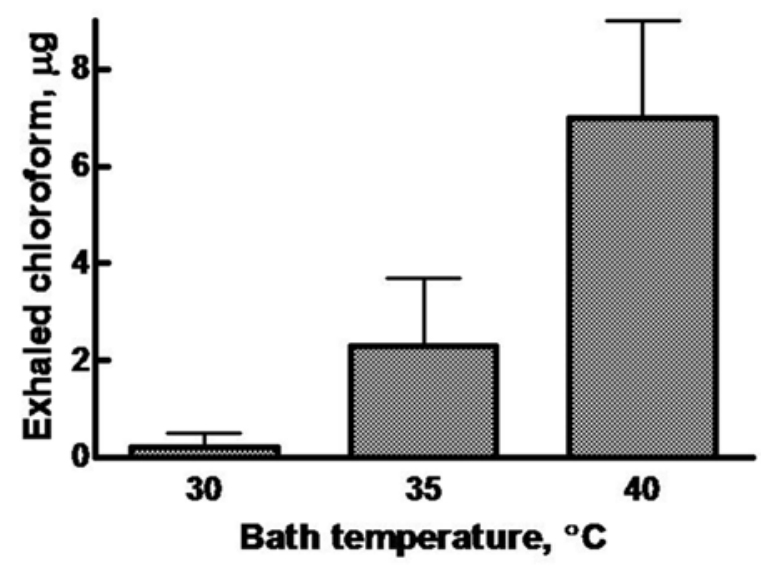

Figure 5. Effect of bath temperature on exhaled chloroform in humans bathing in water containing chloroform. Data plotted as mean + SD. Data from Gordon et al. (11).

temperature, relative humidity, solar radiation, and wind speed. That is, interaction of high ambient temperature and relative humidity equates to greater heat stress resulting in warm skin and profuse sweating. An additional increase in core temperature will simply add to thermal stress, leading to additional sweat production. The respiratory intake of airborne pollutants will be affected by the core and ambient temperature. Heat stress accelerates breathing frequency which alters the intake of the airborne toxicant into the body.

In vitro models using porcine skin are a useful means to study effects of temperature on dermal absorption of organophosphate insecticides and other toxicants (8). In vivo studies in human volunteers showed that cutaneous absorption of parathion increased by $180 \%$ when the ambient temperature of exposure was raised from 28 to $40.5^{\circ} \mathrm{C}(9)$. Plasma nicotine levels in human volunteers wearing nicotine drug patches increased markedly when exposed to a sauna (10). Gordon et al. (11) determined the effect of skin temperature on the dermal absorption of chloroform in a water bath exposure. This study was undertaken because bathing or showering is considered a potential source of exposure to this byproduct of water disinfection. Human subjects bathed at temperatures of 30 to $40{ }^{\circ} \mathrm{C}$ for approximately $30 \mathrm{~min}$ while chloroform absorption was calculated by measuring levels in the exhaled breath (Figure 5). There was very little chloroform absorption at a bath temperature of $30{ }^{\circ} \mathrm{C}$. Chloroform exhaled from subjects bathing at $35{ }^{\circ} \mathrm{C}$ was ten times that when bathing at $30{ }^{\circ} \mathrm{C}$; subjects bathing at $40{ }^{\circ} \mathrm{C}$ exhaled approximately 30 times more chloroform than those bathing at $30{ }^{\circ} \mathrm{C}$. There are two proposed mechanisms for this effect: warmer bath temperatures results in increased capillary blood flow near the skin which shortened the diffusion distance, and the direct physical effect of temperature on the diffusion coefficient of chloroform (11).

The lungs and GI tract are essentially surrounded by the milieu of the thermal core but their role in the intake of toxicants is also influenced by the ambient environment. The intake of an airborne toxicant will be dependent on minute ventilation which, in turn, is affected by ambient temperature. Heat stress increases ventilation resulting in greater intake of airborne toxicants such as ozone (12). Animals that pant to thermoregulate in the heat such as dogs, sheep, and other species could be especially susceptible to this mode of action. Thermal panting refers to a rapid increase in respiratory frequency that is accompanied by an increase in minute ventilation but a decrease in tidal volume (2). Panting mammals have the ability to move large volumes of air across the nasal mucosa to facilitate evaporative heat loss while minimizing the air exchanges with respiratory surfaces that would lead to marked $\mathrm{O}_{2}$ and $\mathrm{CO}_{2}$ imbalances. Finally, the intake of toxicants in the gastrointestinal tract can also be influenced by the thermoregulatory system (Figure 4). This can be pertinent in the study of wildlife species subjected to toxicant or natural toxins in their food supply. The increased energy demands in the winter mean greater intake of food that may be tainted with toxic agents. For example, due to a limited food supply in the winter, some mammals are forced to consume plants with a high content of natural toxins that they would normally avoid in the summer (13).

\subsection{Magnitude and duration of a toxicological response}

One of the key mechanisms to explain the effect of body temperature on chemical toxicity is the direct impact of temperature on the magnitude of effect of a toxicant and duration that it persists in the circulation. That is, the overall efficacy of a drug or toxicant would be expected to depend on both the tissue concentration (and magnitude) and length of time that the toxicant persists in the body (14). In most cases, a reduction in temperature will prolong the duration that the chemical remains in the circulation but reduce the magnitude of toxicity. How a reduction in temperature reduces toxicity is explained below (Section 8.0 Advantages of hypothermic response). When body temperature is reduced, the mechanism(s) responsible for metabolizing and excreting the toxicants will be depressed because the temperature coefficients for these processes are positively affected by temperature. 

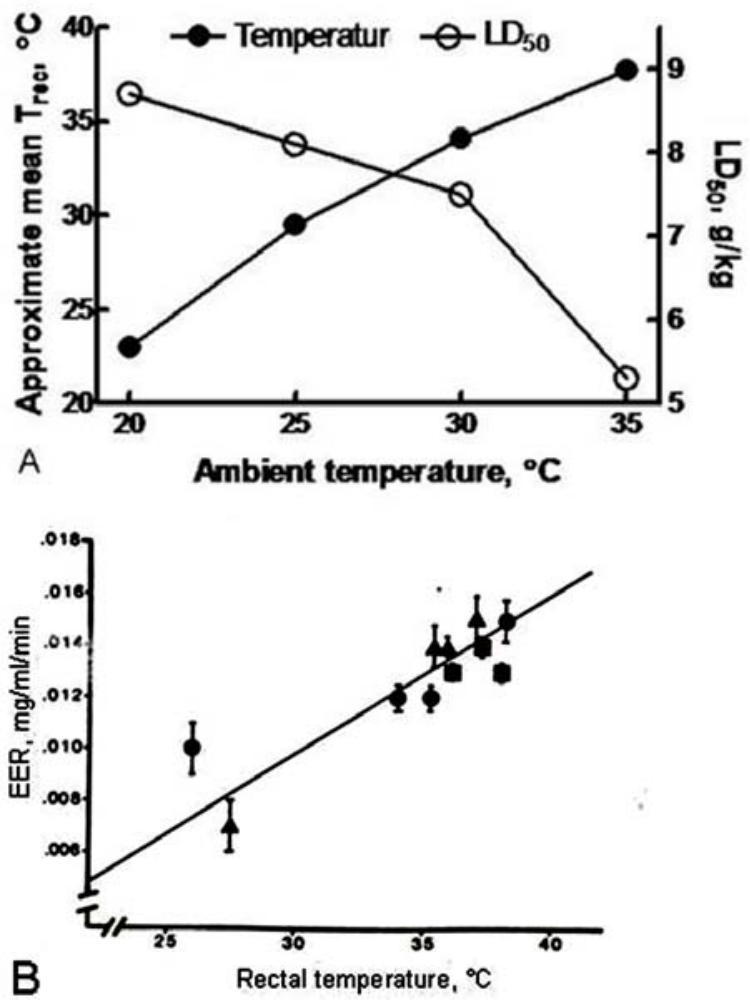

Figure 6. A. Relationship between ambient temperature and rectal temperature on the LD50 of alcohol measured at 8 hours after intraperitoneal dosing in C57 BL/6 J mice. Data graphed from Table 1 of Malcolm and Alkana (15). B. Relationship between body temperature and the elimination rate of ethanol (EER) in mice that were temperature challenged by maintaining at different ambient temperatures after alcohol administration. Graph modified from from Benjanian et al. (16).

Doull (14) developed a general prediction of the response of biological systems to toxic levels of drugs that can also be applied to xenobiotic agents, "Temperature is directly correlated with the magnitude and inversely correlated with duration of drug response in biological systems". In other words, while the concentration of a toxicant will persist longer during hypothermia, the toxicity of the agent is reduced.

The thermoregulatory system of mice and rats can respond rapidly with a hypothermic or hyperthermic response and the integrated thermoregulatory response will have a marked impact on the pharmacokinetics and overall toxicity of a toxicant. Larger mammals such as humans, do not sustain the changes in body temperature as is seen with rodents (see below). Thus, PBPK modelers who develop predictions based on data collected in laboratory rodents should consider how the potential thermoregulatory responses in the smaller species should be extrapolated to larger species.

The clearance and toxicity of ethanol in mice maintained at different ambient temperatures illustrates the magnitude versus duration principle of Doull (14) (Figure
6A,B). The hypothermic properties of ethanol in rodents are well known. Ethanol elicits a marked hypothermic response in mice and the magnitude of hypothermia can be easily modulated with changes in ambient temperature (Figure 6A). In this example, I have plotted the data from a table published by Malcolm and Alkana (15) where they show the relationship between ambient temperature, rectal temperature, and the $\mathrm{LD}_{50}$ for alcohol in mice. This was a very thorough study using large numbers of mice and shows the dramatic effect of core temperature on the lethality of a toxicant. It is interesting to note the dramatic decrease in the $\mathrm{LD}_{50}$ for alcohol when ambient temperature was raised from 30 to $35{ }^{\circ} \mathrm{C}$ resulting in just a $3.5^{\circ} \mathrm{C}$ increase in rectal temperature. On the other hand, the clearance of ethanol from the circulation is inversely dependent on body temperature (Figure 6B). Mice housed at $22{ }^{\circ} \mathrm{C}$ became hypothermic with a core temperature of 35 ${ }^{\circ} \mathrm{C}$ and their ethanol elimination rate was $0.012 \mathrm{mg} / \mathrm{ml} / \mathrm{min}$. When ambient temperature was raised to $35{ }^{\circ} \mathrm{C}$, the hypothermic effect of ethanol was essentially blocked and the clearance of ethanol increased by $30 \%$. Body temperature influences the rate of ethanol elimination, presumably through the thermal modulation of alcohol dehydrogenase activity in the liver $(16,17)$. Hence, a warmer core temperature permits an environment for rapid clearance of the ethanol from the circulation but this is also associated with a marked increase in mortality.

To study the effects of body temperature on the pharmacokinetics of a drug or toxicant, one should consider the specific mechanisms for metabolism and excretion of the agent. Nishida et al (18) recently addressed this issue by clamping body temperature of anesthetized rats and then administering boluses of drugs that are excreted through specific pathways by the liver or kidney (Figure 7). Phenolsulfonphthalein (PSP) is a hydrophilic dye that is excreted into the bile and urine as a free form and as a conjunctive metabolite. At a body temperature of $37^{\circ} \mathrm{C}$, the plasma clearance of PSP shows a typical first order relationship. Lowering core temperature to $32{ }^{\circ} \mathrm{C}$ has a dramatic effect on the clearance of PSP with plasma levels after 240 min nearly 10 times that of animals maintained at $37{ }^{\circ} \mathrm{C}$. Further lowering of temperature to $28{ }^{\circ} \mathrm{C}$ led to a slight lowering of PSP clearance. On the other hand, the clearance of fluoroscein isothiocyante-dextran (FD-4) was not as affected by core temperature; the clearance was essentially the same at 37 and $32{ }^{\circ} \mathrm{C}$ and reduced at $28{ }^{\circ} \mathrm{C}$ (Figure 7). FD-4 is cleared from the plasma primarily by glomerular filtration and it was suggested that autoregulation of renal blood flow and glomerular filtration is preserved at $32{ }^{\circ} \mathrm{C}$ but depressed at $28{ }^{\circ} \mathrm{C}$. Hence, there is no temperature effect on clearance of FD-4 over a relatively wide range of core temperature from 32 to $37^{\circ} \mathrm{C}$ (18). These elegant series of studies demonstrate how the pharmacokinetics of a drug or toxicant will differ depending on the processes for metabolism and clearance.

\section{ACUTE THERMOREGULATORY RESPONSES TO TOXICANTS}

There is an extensive data base on the acute effects of drugs and chemicals on the body temperature of 

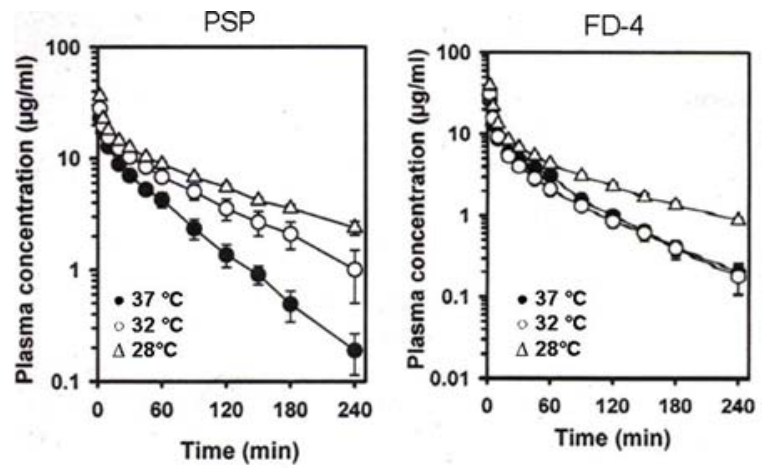

Figure 7. Effects of body temperature on the plasma clearance of PSP, a drug metabolized by the liver, and FD4 , a drug cleared only through glomerular filtration. Graphs modified from Nishida et al. (18).

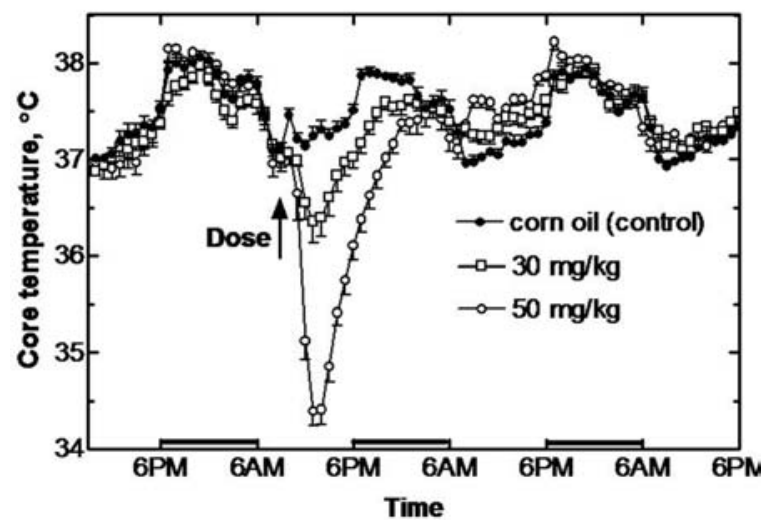

Figure 8. Time-course of core temperature in male LE rats dosed orally with chlorpyrifos, an organophosphate-based insecticide. Data from 54.

rodents and other species $(19,20)$. In test batteries that screen for toxicants, body temperature is frequently used as an indicator of overt toxicity $(21,22)$. A decrease in body temperature in a test species was considered a significant sign of acute toxicity, placed in the same class of sequelae as body weight loss, decreased appetite, and reduced motor activity. It is important to note that in nearly all past studies, especially rodents, the measurement of body temperature was hampered by the stress of the procedure. Most of the studies cited in the above reviews utilized hand-held probes to measure the colonic or rectal temperature of animals that were extensively handled and manipulated. In many of these studies, one finds the so-called baseline core temperature of the control rats to be at least $38^{\circ} \mathrm{C}$, a value which is at least one degree Centigrade above the rat's normal daytime temperature (see Figure 2). In other words, the rats in all treatment groups (controls included) are likely to be hyperthermic before the initiation of a treatment. This hyperthermic state can obviate any subtle effects that a toxicant at low doses would have on body temperature and limits the usefulness of body temperature as a sensitive indicator of toxicity. Radiotelemetry provides the best means of monitoring the core temperature of undisturbed animals (23). Recently, a set of recommendations was developed for researchers studying the effects of drugs and toxicants on the thermoregulatory system (Table 2). Overall, the best assessment of the effects of a toxicant on thermoregulation is made in undisturbed animals monitored remotely with telemetry. Restraint or repeated insertion of a temperature probe is the least desired methods because of the stress-induced changes in body temperature.

Hypothermia is a consistent thermoregulatory response of mice and rats dosed acutely with a variety of toxic agents, including insecticides, metals, airborne toxicants, and solvents (1). One example that typifies the thermoregulatory response of the rat to an organophosphate-based insecticide (chlorpyrifos) shows a period of hypothermia, followed by recovery to control levels and then a delayed rise in the daytime core temperature that may persist for several days (Figure 8). Researchers assessing the effects of ambient temperature on the thermoregulatory response typically found that lower ambient temperatures exacerbated the hypothermic response of toxic chemicals (1). This led to the supposition that the hypothermia was a result of dysfunction of the thermoregulatory system through impairment in metabolic thermogenesis and/or the ability to conserve heat loss.

\subsection{Forced and regulated changes in temperature}

Body temperature can change in a forced or regulated fashion following exposure to a drug or toxicant (Figure 9). If the change in body temperature can be identified as regulated then one can be assured that the toxicant is affecting CNS thermoregulatory mechanisms and is altering the set-point temperature $\left(\mathrm{T}_{\text {set }}\right)$. A forced response could be mediated with or without activation of CNS pathways and $\mathrm{T}_{\text {set }}$ is unaffected by the toxicant (24, 25). Fever epitomizes an increase in the regulated body temperature. During fever there is a transient period where $\mathrm{T}_{\text {set }}$ is suddenly elevated above the core temperature (Figure 9A). That is, with an infection there is an inflammatory response and release of a variety of cytokines and other factors into the circulation. Cytokines such as interleukin (IL)-1 and IL-6 directly affect the CNS thermoregulatory centers in the hypothalamus resulting in an increase in $\mathrm{T}_{\text {set }}$. The animal responds as if it was cold and selects warmer ambient temperatures and activates thermoeffectors to increase heat production (shivering and non-shivering thermogenesis) and reduce heat loss (peripheral vasoconstriction).

Thermal physiologists view infectious fever as the corner stone of a set-point elevation. Non-infectious fevers are not as well studied but can be manifested during the course of recovery from a variety of pathophysiological insults. For example, the application of radiotelemetry to monitor core temperature in undisturbed rats reveals regulated elevations in core temperature that persist for several days following traumatic brain injury (26) and burn injury (27). As discussed earlier, acute administration of toxicants such as ethanol and anticholinesterase agents to rats elicits an initial hypothermic response; however, recovery from the acute hypothermic response is characterized by a fever-like elevation in core temperature 
REGULATED HYPERTHERIA (FEVER)

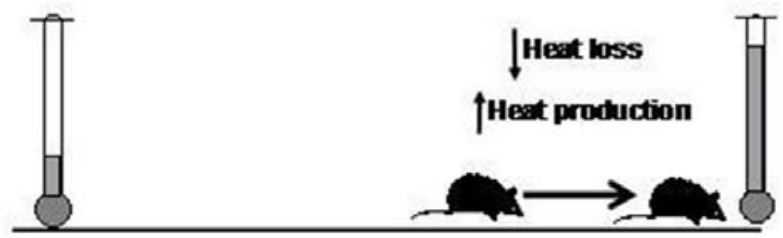

A

FORCE HYPOTHERA

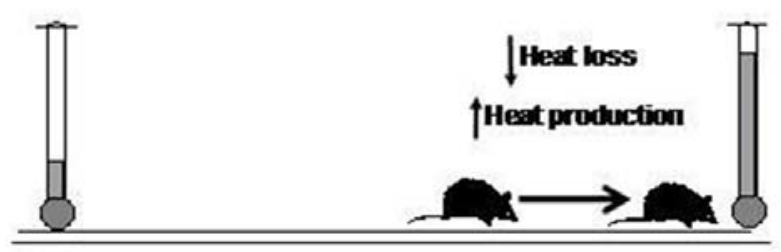

C
FORCED HYPERTHEREIK

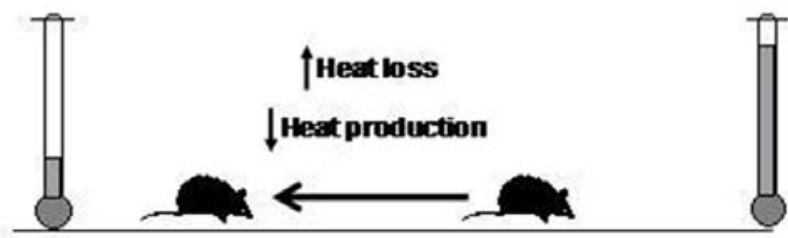

REGULATED HYPOTHEREA

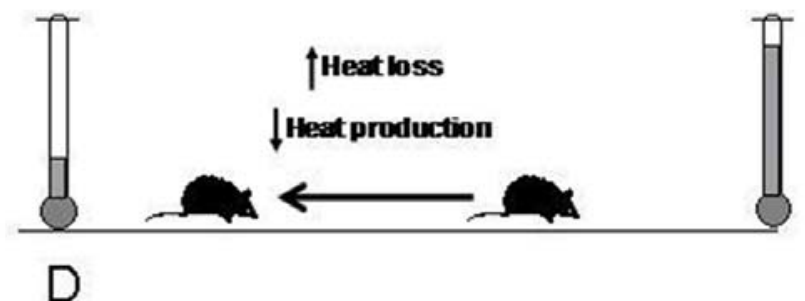

Figure 9. Summary of the possible thermoregulatory response to a toxicant or drug. A rodent under normothermic conditions prefers an ambient temperature in the thermoneutral zone $\left(\sim 30^{\circ} \mathrm{C}\right)$. A chemical, pyrogen, or other agent may affect the central control of thermoregulation or the ability for thermoeffectors to control body temperature leading to forced or regulated changes in core temperature. See text for details. From Gordon, $(1,24)$.

(see section: 9.0 Delayed and chronic effects). Considering the association between the term fever and exposure to infectious agents, this author prefers the term regulated hyperthermia (to describe these non-infectious type elevations in core temperature).

As the hyperthermic response progresses during regulated hyperthermia, there is eventually an equaling of $\mathrm{T}_{\text {set }}$ and core temperature and the animal reaches a steady state with an elevated body temperature. Administration of antipyretic drugs results in a sudden lowering of $T_{\text {set }}$ to normal, a response accompanied with a preference for cooler temperatures and activation of thermoeffectors to increase heat loss (e.g., sweating, peripheral vasodilation). During forced hyperthermia, core temperature increases above $\mathrm{T}_{\text {set }}$ as would occur by exposure to high ambient temperatures or by administering toxicants or drugs that stimulate metabolic thermogenesis but without affecting the CNS control mechanisms (Figure 9B). Heat production is minimal and thermoeffectors are activated to increase heat loss to lower core temperature. A colder environment is sought to facilitate heat loss and lower body temperature to normal. Toxic agents such as 2,4-dinitrophenol that uncouple oxidative phosphorylation and raise heat production are examples of forced hyperthermia. Forced hypothermia refers to the state when core temperature is forced below $\mathrm{T}_{\text {set }}$, as would occur during acute cold exposure or treatment with toxicants or drugs that impair metabolic thermogenesis without affecting CNS control mechanisms (Figure 9C). The organism responds with an activation of thermoeffectors to minimize heat loss and increase heat production. A warmer environment is sought to reduce heat loss. Regulated hypothermia occurs when a chemical or drug interacts with the CNS thermoregulatory centers and elicits a sudden lowering of $\mathrm{T}_{\text {set }}$ (Figure 9D).
This is essentially opposite to that of a fever because the organism reacts as if it was feeling warm, seeks cooler temperatures and activates thermoeffectors to increase heat loss and reduce heat production. These thermoeffector responses persist until core temperature is equal to $\mathrm{T}_{\text {set }}$. The majority of toxic agents elicit a regulated hypothermic response when administered to rodents (see below). One also finds the term anapyrexia used to describe a pathological condition in which there is a regulated decrease in body temperature (2). Anapyrexia and regulated hypothermia are essentially the same but the latter is preferred, especially when describing the responses to toxic agents.

\subsection{Is toxicant induced hypothermia forced or regulated?}

To assess if a toxic insult is impairing the thermoregulatory system, one must first understand if the chemical's effect is forced or regulated. This information would aid in distinguishing between a CNS versus peripheral effect of a toxicant. Measuring core temperature alone is not sufficient to decide if the chemical is eliciting a forced or regulated change in temperature. Performing a thermoregulatory profile in a rodent exposed to a toxicant (e.g., Figure 1) can help elucidate if the change in body temperature is forced or regulated. For example, an increase in tail skin blood flow and a reduction in metabolic rate in a cold environment would suggest a CNS drive to lower core temperature. In fact, behavioral thermoregulation measured simultaneously with core temperature is usually sufficient to distinguish between forced and regulated changes in core temperature. Clark and Lipton (28) were the first to use a measure of behavioral thermoregulation (operant pressing for heat) to study the nature of toxins that lowers body temperature. 


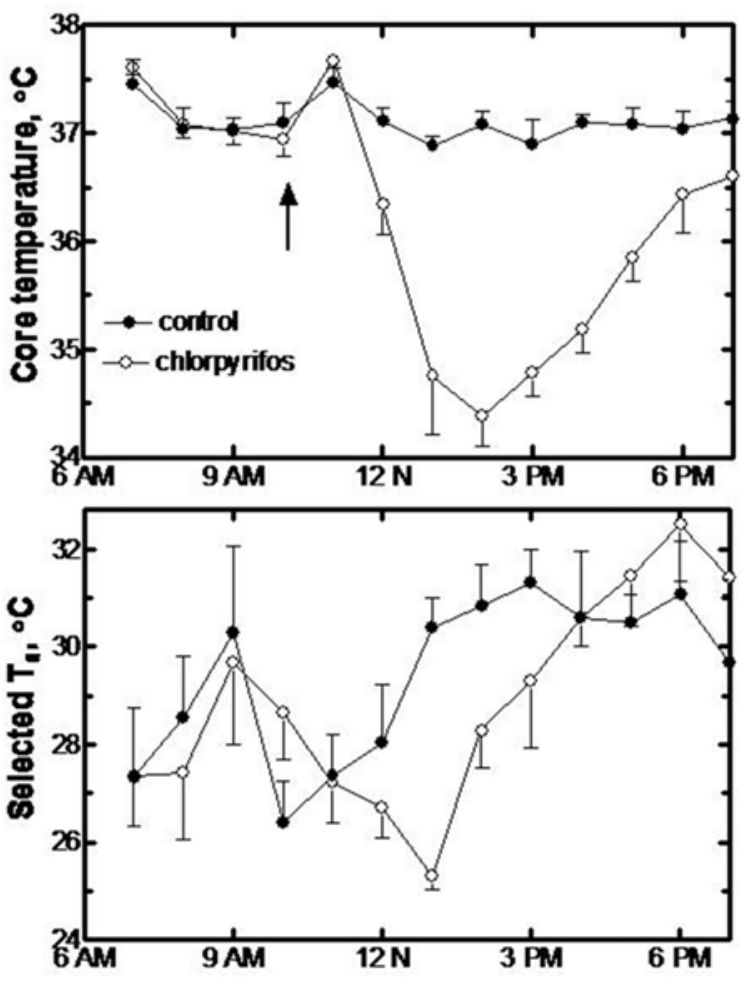

Figure 10. Behavioral thermoregulatory response of female Long Evans rats dosed with chlorpyrifos and housed in a temperature gradient to monitor selected ambient temperature and core temperature (from 29).

They found that injections of the toxins tetrodotoxin and saxitoxin into the lateral cerebral ventricle of cats led to similar reductions in core temperature regardless of whether the animals had access to an operant system to bar press for heat. It was concluded that these toxins elicited a downward shift in the set-points for behavioral and physiological thermoregulatory activity.

\subsection{Importance of behavioral thermoregulation}

This same principle can be applied to the study of the thermoregulatory effects of toxicants in rodent models using a temperature gradient or operant system. Temperature gradients mimic a natural type of option for the animal to seek out its optimum thermal environment. If the toxicant impairs motor activity, behavior in the temperature gradient can still be displayed with little energy expenditure. Moreover, thermoregulatory behavior in a gradient can be learned quickly. Operant systems are also useful in toxicology studies because the animals can be instrumented easily to monitor physiological processes while quantifying its behavior. However, considerable training is needed for animals to learn to use thermoregulatory behavior in an operant system and the animal must continually work to maintain thermal reinforcements.

Our laboratory and others have used the temperature gradient to monitor core temperature via telemetry and selected ambient temperature of rats and mice following exposure to a variety of toxic chemicals. The time-course of selected ambient temperature and core temperature in the rat exemplifies a regulated hypothermic response (Figure 10). The rats were dosed with chlorpyrifos, an anti-ChE based insecticide that leads to stimulation of cholinergic pathways. When dosed with a control vehicle (corn oil), there was a transient decrease in selected temperature that reflected a heat dissipatory response from the stress of handling and injection. Following chlorpyrifos treatment, selected ambient temperature decreased from 30 to $25{ }^{\circ} \mathrm{C}$ and the behavioral response preceded a $2.5{ }^{\circ} \mathrm{C}$ decrease in core temperature (Figure 10). At the nadir of the decrease in core temperature, selected temperature exhibits an abrupt increase, a response that facilitated the recovery from hypothermia. Other organophosphates such as DFP elicit regulated hypothermic responses in rats housed in a temperature gradient $(29,30)$ In another example, mice dosed with selenium select cooler temperatures in a temperature gradient (Figure 11). Their core temperature was not measured in the gradient but was measured in separate groups of animal housed at a warm temperature of $33{ }^{\circ} \mathrm{C}$ to attenuate the hypothermic response or at a cooler ambient temperature that approximated the temperatures they preferred after selenium exposure. The cooler temperatures selected in the temperature gradient indicate that mice allow core temperature to become hypothermic when given the opportunity to choose their thermal environment (31).

With few exceptions (discussed below) acute exposure to most toxic chemicals elicits hypothermia in mice and rats (1). A relatively small number of studies have used additional techniques to measure autonomic and/or behavioral thermoeffectors to determine the nature of the hypothermic response. That is, to show whether the hypothermic responses is forced or regulated. Mice or rats placed in a temperature gradient and given toxic doses of heavy metals (nickel, cadmium, lead), solvents (ethanol, sulfolane), and anti-ChE insecticides (chlorpyrifos, DFP) will consistently prefer cooler ambient temperatures as they become hypothermic (for review, see 1, 25, 32). So far, there is no report that an animal will select a warm temperature to block the acute hypothermic effects of a toxicant. It follows that the majority of toxic agents studied in mouse and rat that elicit hypothermia are likely evoking a regulated hypothermia. The hypothermic response is generally an adaptive response that improves survival to the toxicant.

It is timely to note that insults other than toxic chemicals also elicit similar thermoregulatory responses in animals housed in a temperature gradient. Acute hypoxia, hemorrhage, uremia, and endotoxemia elicit hypothermia and preference for cooler temperatures (1). This raises the question as to the possible mechanisms of action to explain regulated hypothermia.

\subsection{Mechanism of action}

Microinjection of select neurotransmitters and neuromodulators into the CNS can elicit a pattern of regulated hypothermia, suggesting that the toxic-induced hypothermic response could be mediated through selective 


\section{BEHAVORAL RESPONSE}

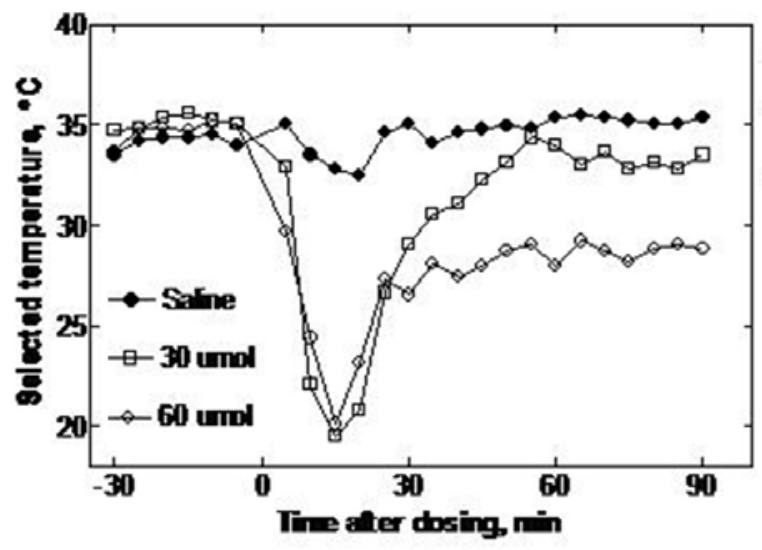

CORE TEMPERATURE RESPONSE
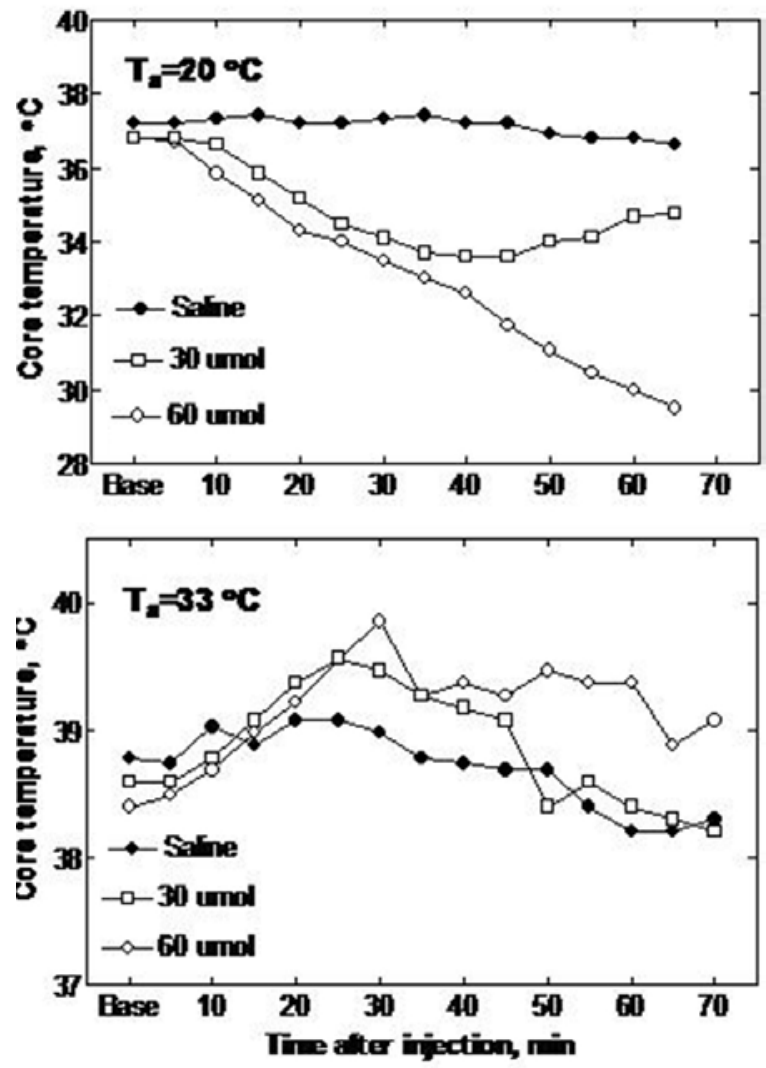

Figure 11. Effect of acute selenium exposure on core temperature measured at fixed ambient temperatures of 20 and $33{ }^{\circ} \mathrm{C}$ and on selected ambient temperature when mice were housed in a temperature gradient (modified from Watanabe et al. (31).

activation of pathways in the CNS thermoregulatory centers $(19,20)$. Depending on species and ambient temperature, neurotransmitters administered into the cerebral ventricles or directly into the preoptic area/anterior hypothalamus (POAH) will elicit hyperthermic or hypothermic responses.
The best understood mechanism of action of regulated hypothermia has been documented with the antiChE agents. The stimulation of CNS muscarinic pathways appears to be a primary cause of the acute hypothermic responses elicited by antiChE insecticides. Administration of relatively high doses of cholinomimetic agents into the CNS will elicit hypothermic responses (for review, see 33). Upon activation of muscarinic pathways in the thermoregulatory centers of the POAH, the heat loss pathway is stimulated, meaning that the animal reacts as if it is hot and attempts to lower core temperature by increasing skin blood flow and selecting cooler ambient temperatures. Co-administration of muscarinic antagonists such as scopolamine or atropine blocks most of the hypothermic response elicited by antiChE agents $(34,35)$. On the other hand, one will find a hyperthermic response with microinjection of relatively low doses of cholinomimetics into the CNS. The mechanism of action for other most other toxicants is not as well understood. How toxicants with a diversity of structures elicit a similar hypothermia response is not known. It is possible that toxicants are capable of eliciting a central CNS response through a peripheral mechanism of action.

\subsection{Recommended approach to study thermoregulatory effects of toxicants}

Incorporation of radiotelemetry into a study on the thermoregulatory mechanisms of action of a toxicant is highly recommended. Telemetry applied to animals maintained at standard room temperatures is extremely useful; however, utilizing a telemetry approach in mammals that are exposed to cold, thermoneutral, and heat stress conditions will provide critical information on how the toxicant affects thermoregulatory pathways that otherwise might not be detected when studying the effects at room temperature. Finally, incorporation of a system to assess how the toxicant affects the thermal preference of the animal will certainly allow researchers to decipher if the toxicant has effects on central thermoregulatory control.

\section{THERMOREGULATORY EFFECTS OF ALCOHOL}

The toxicity and mechanism of action of alcohol (ethanol) on the thermoregulatory system has been well studied in experimental animals and humans. Hence, alcohol is an ideal agent to study in the extrapolation of thermoregulatory responses of toxicants from laboratory mammals to humans. It was well known that acute exposure to alcohol via an oral, inhalation, or parenteral route elicits hypothermia in rats and mice housed at standard laboratory temperatures $\left(\sim 22^{\circ} \mathrm{C}\right.$ ) (for review, see $1,36)$. The hypothermic effect of alcohol increases in a near linear fashion with reductions in ambient temperature below the thermoneutral zone. Alcohol elicits hyperthermia as ambient temperature increases above the thermoneutral zone. In view of this response, Myers (37) termed the thermoregulatory response of alcohol in the rat as a "poikilothermic" response, meaning that with acute intoxication, the rat's thermoregulatory system becomes dependent on the prevailing ambient temperature. In other 
words, alcohol intoxication renders thermal homeostasis to a condition as is normally observed in most of the so called lower vertebrate (reptiles, amphibians, fish) that, compared to mammals and birds, posses little autonomic control of thermoregulation.

Poikilothermic species do have behavioral control of their body temperature and can maintain a relatively stable core temperature when housed in an environment that permits behavioral thermoregulation. The same is true for rats and mice exposed to alcohol and given a choice of selecting from a range of ambient temperatures. Studies in our laboratory and others showed that when rats and mice are dosed with alcohol and allowed to behaviorally thermoregulate in a temperature gradient, they selected cooler ambient temperatures concomitant with a reduction in body temperature (38-40). Thus, alcohol, like many other toxicants, evokes an apparent regulated hypothermia in rodents. Indeed, Lomax et al. (42) postulated in 1980 that alcohol elicited a reduction in the set-point temperature since they noted that rats dosed with alcohol became hypothermic and avoided a heat source.

Measuring autonomic and behavioral thermoeffectors in humans dosed with alcohol under controlled conditions provides evidence of a regulated hypothermic response similar in some respects to that seen in rodents. Yoda et al. (43) have recently studied the autonomic and behavioral thermoregulatory responses of human volunteers given alcohol and maintained at ambient temperatures above and below the thermoneutral zone (Figure 12A\&B). This is an essential step to understand if alcohol elicits a forced or regulated reduction in core temperature. When subjects were maintained at an ambient temperature of $18{ }^{\circ} \mathrm{C}$ and given distilled water or $0.36 \mathrm{~g} / \mathrm{kg}$ alcohol, core temperature and mean skin temperature decreased in a similar manner regardless of treatment (Figure 12A). Metabolic rate was slightly lower in the alcohol group. While body temperature was unaffected by alcohol treatment, the whole body sensations of cold and thermal discomfort seen in controls were attenuated in the subjects given alcohol (Figure $12 \mathrm{C}$ ). On the other hand, when subjects were maintained at an ambient temperature of $33{ }^{\circ} \mathrm{C}$ (i.e., just above their thermoneutral temperature) and given the same dose of alcohol as the subjects tested at $18^{\circ} \mathrm{C}$, there was a marked elevation in skin blood flow and sweating (Figure 12B) along with feeling of warmth. Their core temperature fell by $0.3{ }^{\circ} \mathrm{C}$ relative to the control group (44).

These human studies seem to pose a contradiction to the hypothesis that alcohol elicits a regulated hypothermia. On the one hand, the observed increase in thermoeffectors activity for heat loss in humans housed above thermoneutral temperatures supports the notion that acute alcohol elicits a heat dissipating response, leading to hypothermia. On the other hand, does the lack of an alcohol-induced hypothermia in cold-exposed humans contradict the concept of regulated hypothermia? Based on the rodent studies, if alcohol elicits hypothermia at a given ambient temperature, then lowering the ambient temperature from 33 to $18{ }^{\circ} \mathrm{C}$ should have resulted in a greater hypothermic response. But there are several factors to consider in comparing rodents to humans. Peripheral vasoconstriction appears to have a critical role in overriding the hypothermic effects of alcohol in humans. Even though alcohol elicits a feeling of warmth in the cold, the stimulus to increase vasomotor tone by alcohol appears to be overridden by the cold-induced stimulus to minimize skin blood flow (Figure 12A). The sensation of a feeling of warmth following moderate alcohol consumption at temperatures above thermoneutrality should lead to a selection of a cooler ambient temperature. These responses are homologous to that of rodents with the exception that the hypothermia is relatively miniscule in adult humans.

Under standard laboratory conditions, a small hypothermic response can be elicited in humans who consume moderate doses of alcohol (see Figure 15). As discussed later, a large body mass is a key factor in limiting the hypothermic response to toxicants and drugs. Thus, the marked hypothermic response seen in small laboratory rodents will be relatively meager in healthy adult humans. On the other hand, there are emergency room reports showing marked hypothermia in some instances. These cases arise from acute intoxication of individuals in poor health combined with exposure to cold temperatures (36).

\section{TOXIC CHEMICALS ELICITING HYPERTHERMIA}

There are three classes of toxic chemicals that induce marked hyperthermia in laboratory rodents: DDT, 2,4- dinitrophenol (DNP) and certain pyrethroids. DDT is an organochlorine that was well studied for its thermoregulatory and other effects prior to being banned. It is tremorigenic and a convulsant and is one of the few pesticides that can elicit an acute and apparently lethal increase in the core temperature (45). The thermoregulatory effects of DDT are dependent on ambient temperature. When given a lethal dose of DDT $(1000 \mathrm{mg} / \mathrm{kg})$ and housed at $22{ }^{\circ} \mathrm{C}$, tail skin temperature of the adult rat begins to increase prior to any change in core temperature by 3 to 5 hours after injection (46). There is then a precipitous decrease in tail skin temperature that is concomitant with a marked increase in core temperature. At the point of death, around $6 \mathrm{hr}$ after dosing, core temperature is $40-42{ }^{\circ} \mathrm{C}$ while tail skin temperature is nearly below pretreatment levels. It is interesting to note that if the DDT-treated rat is placed in a cold room maintained (e.g., 3 to $4{ }^{\circ} \mathrm{C}$ ), core temperature will fall dramatically, reaching near hypothermic lethal levels within a few hours (46). Hence, in spite of the intense tremorigenic activity of this agent, DDT-treated rats in the cold are unable to thermoregulate against a cold stress that is well tolerated by untreated rats. As with other tremorigenic compounds such as kepone, the heat from tremor in rats dosed with DDT appears to contribute little to the overall heat balance of the rat.

DNP is a classic uncoupling agent of oxidative phosphorylation and causes marked elevations in oxygen consumption. It is interesting that there is relatively little known on the thermoregulatory mechanisms of DNP in spite of the long history of its use as a herbicide (47). 
Toxic chemicals and thermoregulation
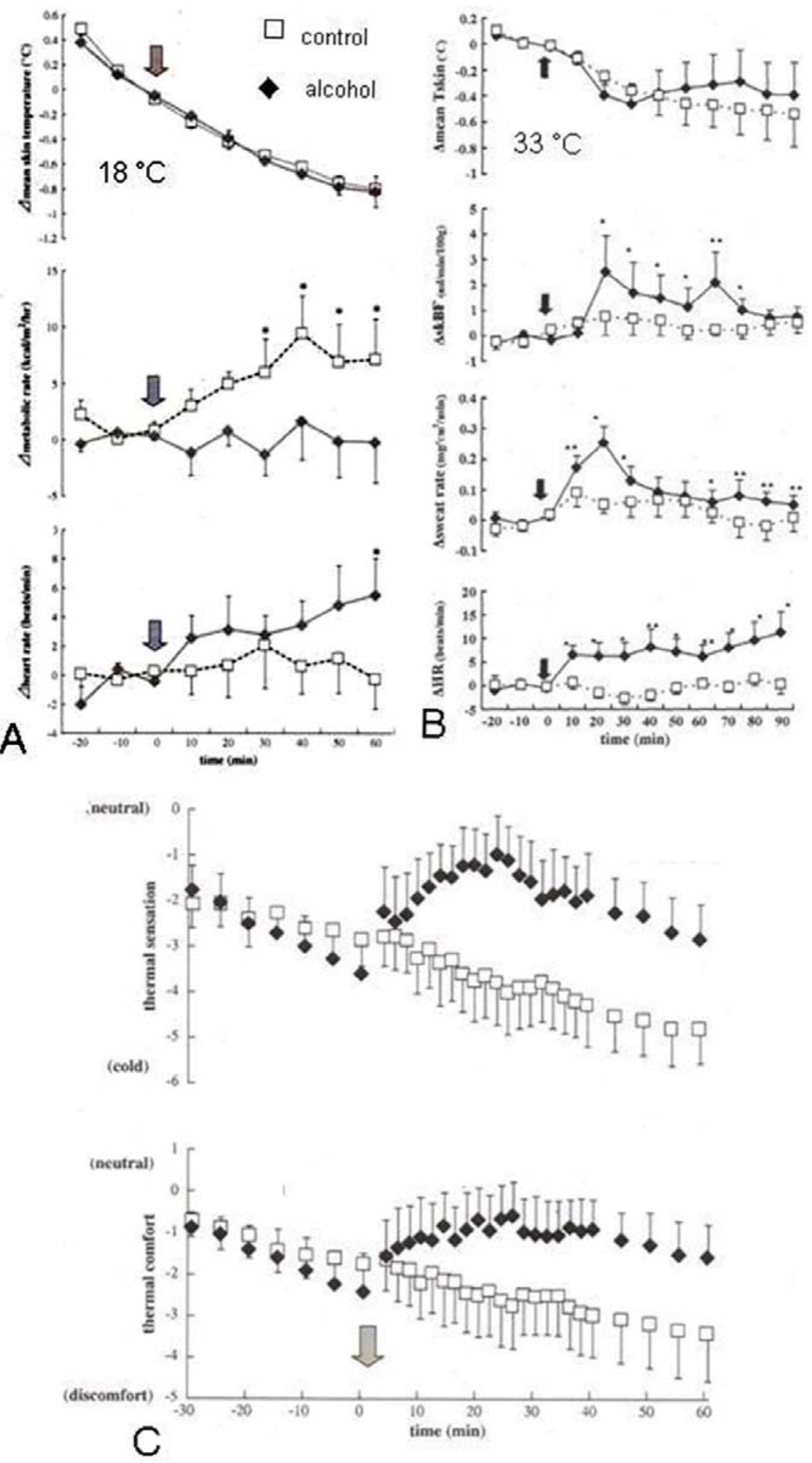

Figure 12. Effect of alcohol consumption $(0.36 \mathrm{~g} / \mathrm{kg})$ on autonomic thermoeffectors in a cold environment of $18^{\circ} \mathrm{C}(\mathrm{A})$, a warm environment of $33{ }^{\circ} \mathrm{C}(\mathrm{B})$, and on thermal comfort at an ambient temperature of $18{ }^{\circ} \mathrm{C}(\mathrm{C})$. Arrows indicate time of alcohol consumption in human volunteers. Positive and negative numbers of thermal comfort index indicate warm and cold sensation, respectively. Graphs modified from Yoda et al. $(43,44)$. 
Toxic chemicals and thermoregulation

Table 2. Recommendations for rodent thermometry in toxicology studies, starting with the best and ending with least ideal method

1. Radiotelemetry. Monitoring of a temperature probe surgically implanted in a thermal core of the animal (abdomen, brain). Remote monitoring of animals housed in a vivarium isolated from disturbances from personnel. Maintenance of animals in a thermoneutral environment and/or with bedding that allows animals to adjust insulative qualities of microenvironment.

Advantages: Provides best measure of true thermoregulatory patterns of mice and rats; continuous, automated monitoring of core temperature 24 hours/day. Allows for observations of acute, sub-chronic, and chronic effects of drugs and toxicants.

Disadvantages: Expensive start up costs; surgical implantation with anesthesia required.

2. Subcutaneous transponder chips. Chips that encode animal ID and possess temperature measuring capability are implanted under skin through a trocar. ID and temperature data can be downloaded with handheld receiver.

Advantages: Less costly than telemetry; accurate measure of the subcutaneous temperature; no surgery or anesthesia required.

Disadvantages: Subcutaneous temperature is not a measure of the core temperature; personnel must be in close proximity to animal to position receiver to collect temperature data. Data collection not automated; no 24 hour monitoring.

3. Infrared thermography.

Advantages: Provides non-contact measurement of skin temperature which can be valuable for interpreting effects of toxicants and drugs. Hand held devices relatively inexpensive.

Disadvantages: Skin temperature is not equal to core temperature. Skin temperature does not necessarily parallel the core temperature. Continuous, automated monitoring is costly. Personnel must generally be in close proximity to animal to make measurements.

4. Colonic/rectal temperature probes (unrestrained rodents). An accurate measurement of the core temperature can be determined, provided that the animal is undisturbed for sufficient time immediately prior to the insertion of the probe. Temperature is measured within seconds prior to any stress-induced changes in temperature.

Advantages: Inexpensive and easy to perform; provides an accurate, a single time point measurement.

Disadvantages: Technique evokes stress resulting in eventual change in body temperature from handling; repeated use with the device leads to inaccurate estimates of the true resting core temperature. Difficult to use with multiple housed animals because disturbance causes stress and elevation in temperature as multiple animals are being measured.

5. Colonic/rectal temperature probes in semi-restrained animals (e.g., probe inserted and taped to tail).

Advantages: Inexpensive, accurate measure of core temperature

Disadvantages: Continuous stress of probe insertion leads to abnormally high body temperatures in rats. Animals must be restrained or carefully observed to assure probe remains in place.

6. Restraint with colonic probe.

Advantages: Restrained animal easy to manipulate (i.e., nose only inhalation).

Disadvantages: Marked effects on thermoregulatory system. Rodents are much more sensitive to ambient temperature when restrained. Unable to use behavior and thermoeffectors as effectively when restrained.

Modified from 23
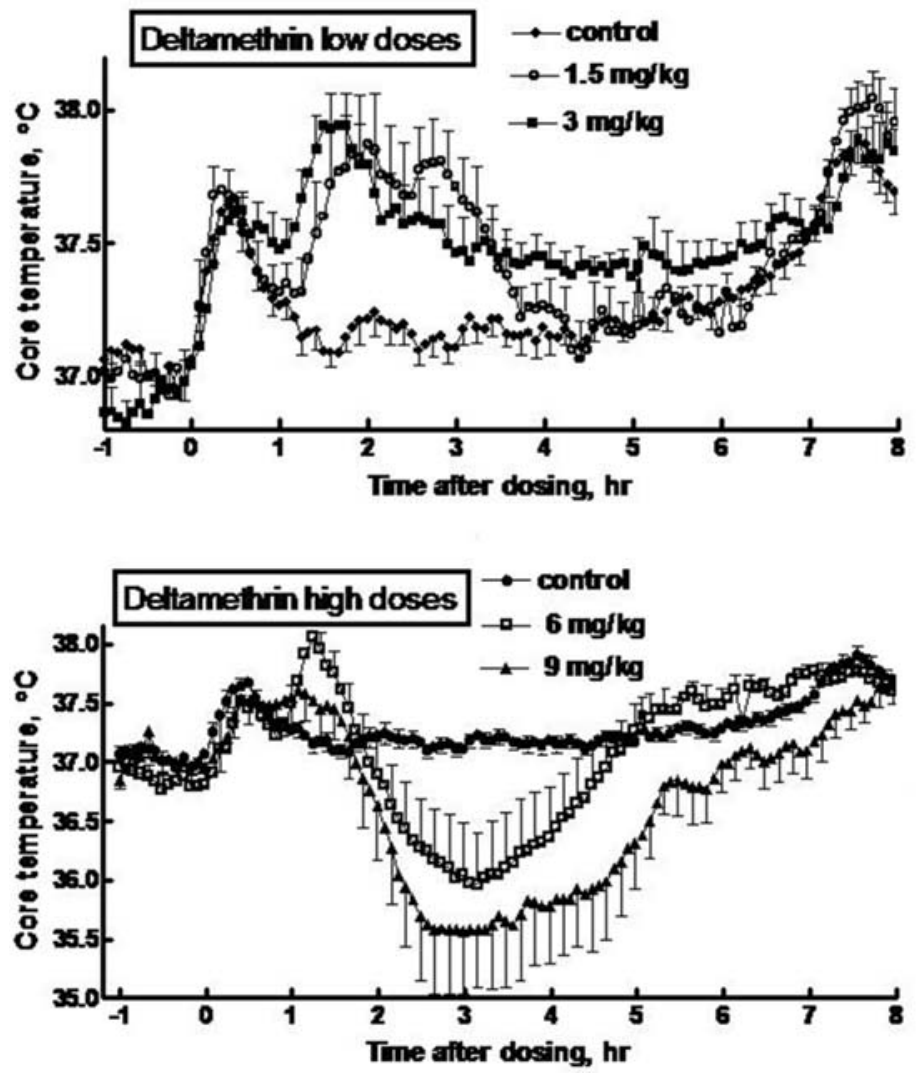

Figure 13. Time course of core temperature in rats administered the type II pyrethroid, deltamethrin. Upper panel: initial response to deltamethrin; Lower panel: Delayed core temperature response the day after dosing. Data from Wollansky et al. (61). 


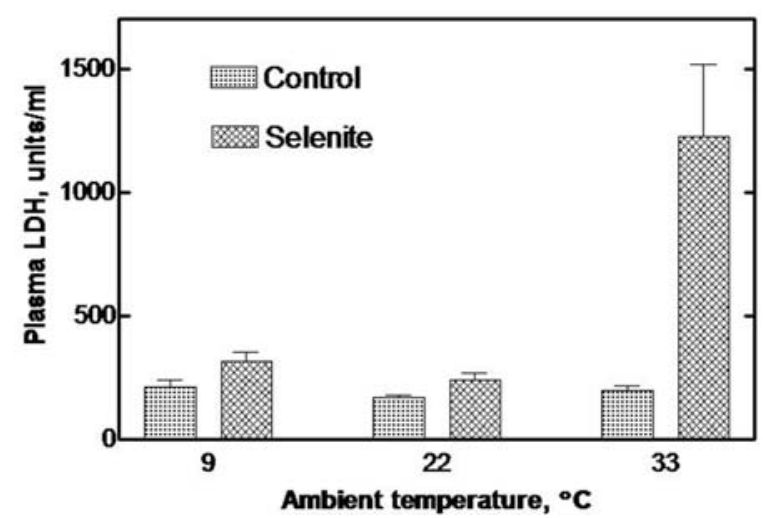

Figure 14. Effect of $45 \mathrm{umol} / \mathrm{kg}$ sodium selenite and simultaneous exposure to ambient temperatures of 9,22 , or $33{ }^{\circ} \mathrm{C}$ for 3 hours on plasma levels of lactate dehydrogenase (LDH) in the mouse when measured three days after selenite exposure. Data plotted as mean + S.E. Data taken from Watanabe et al. (51).

Intravenous infusion of DNP to awake rats caused a near instantaneous elevation in metabolic rate, ventilatory frequency, and tidal volume concomitant with a steady rise in body temperature. The oxygen consumption increased from 34 to $51 \mathrm{ml} / \mathrm{kg} / \mathrm{min}$ following repeated intravenous injections of DNP with a total dose of $24 \mathrm{mg} / \mathrm{kg}$ in rats maintained at an ambient temperature of $15{ }^{\circ} \mathrm{C}$. The increase in metabolic rate was associated with a $1.1{ }^{\circ} \mathrm{C}$ increase in core temperature. Pentachlorophenols (PCP) have antifungal properties and have been used for many years as wood preservatives. These compounds also act as uncoupling agents of oxidative phosphorylation. Human exposures in the timber industry were common with cutaneous and inhalation routes. Dangerous, prolonged elevations in core temperature, accompanied with profuse sweating have been reported in workers subjected to acute PCP exposure (for review, see 1). For example, a 22-yearold male exposed to PCP on the work site was admitted to the emergency room with a core temperature of $41.8^{\circ} \mathrm{C}$; within 22 hours core temperature had increased to $42.2^{\circ} \mathrm{C}$ and the subject died (4). One generally finds that the hyperthermia in these studies is termed fever or hyperpyrexia. However, assuming that the CNS control of body temperature is unaffected by PCP, then it can be assumed that the rise in core temperature is essentially a forced hyperthermia and not a true fever (see Figure 9).

The pyrethroid-based insecticides are widely used in domestic and agricultural applications but there is surprisingly little information on their effects on thermoregulation. Pyrethoids are generally classified as Type I or Type II, depending on their neurophysiological and behavior effects (see 48 for summary). Type I pyrethroids keep sodium channels open momentarily (i.e., milliseconds) whereas Type II agents keep channels in an open state for minutes. In general, Type I pyrethroids elicit hyperthermic responses whereas Type II elicit hypothermia. However, the pyrethroid thermoregulatory literature is based entirely on studies using colonic probes. Recent application of radiotelemetry to monitor core temperature reveals interesting dose-response properties of these compounds (Figure 13). For example, in rats monitored by radiotelemetry, the thermoregulatory response to deltamethrin, a commonly studied Type II agent shows abiphasic dose-response of hyperthermia at low doses and hypothermia at high doses (Figure 13). In spite of all that is known on the neural mechanisms of pyrethroid toxicity, there is no understanding of how certain classes and doses of pyrethroids elicit hypothermic or hyperthermic responses in the rat. Telemetric observations in undisturbed animals also showed a delayed elevation in core temperature persisting during the day after acute exposure. It is of interest to note the similarity between the dose response to deltamethrin to the thermoregulatory dose response to lipopolysaccharide (LPS). These compounds have distinct mechanisms of action but have similar thermoregulatory dose responses. Low doses of LPS elicit a regulated febrile response but administration of high doses of LPS elicits a regulated hypothermic response characterized by hypothermia and preference for cooler temperatures in a temperature gradient (65).

\section{ADVANTAGES OF A HYPOTHERMIC RESPONSE}

The direct effects of body temperature on the toxicity of drugs and toxic chemicals were recognized by the turn of the last century (for review, see 49). Prior to the development of modern analytical methods, frogs were often used as a species for bioassays of drugs and other chemicals. Because body temperature of frogs and other poikilotherms is directly dependent on ambient temperature, it was quickly determined in these early studies that body temperature had a marked effect on pharmacokinetics and toxicology of drugs and other chemicals. For example, studies in the 1890's on the toxicity of cholchicine showed that the frog was 400 to 500 times as sensitive when dosed at an ambient temperature of $32{ }^{\circ} \mathrm{C}$ as compared to $20^{\circ} \mathrm{C}$. Toxicity studies in amphibians maintained at different temperatures led to a general conclusion for cholchicine that "...the temperature of the body is the chief factor influencing toxicity" (49). The lethal dose (e.g., $\mathrm{LD}_{50}$ ) has conventionally been used in rodent studies as a benchmark of toxicity. While tests using death as an end point are rarely used in current research studies, these older studies are very useful for illustrating how overt toxicity is affected by body and ambient temperature.

The body temperature of poikilothermis will be equal to the ambient temperature provided there are no behavioral options to alter heat gain or loss (e.g., shade or sun seeking behavior). Homeotherm core temperature is generally independent of ambient temperature but the additional metabolic stress to thermoregulate in a warm or cold environment can affect the sensitivity to toxicant exposure. The toxicity of a toxicant will be modulated depending on whether the animal is hypothermic, normothermic, or hyperthermic. Keplinger et al. (50) was one of the first to perform systematic studies on the lethal dose of a variety of drugs and chemicals in the rat. The approximate lethal dose of 58 compounds was determined in rats housed for 45 minutes before and 72 hours after 
Table 3. Effect of ambient temperature $\left(\mathrm{T}_{\mathrm{a}}\right)$ on the approximate lethal dose $(\mathrm{mg} / \mathrm{kg})$ of a variety of toxic chemicals administered intraperitoneally in rats

\begin{tabular}{|l|l|l|l|}
\hline Chemical & $\mathbf{T}_{\mathbf{a}}=\mathbf{8}^{\circ} \mathbf{C}$ & $\mathbf{T}_{\mathbf{a}}=\mathbf{2 6}{ }^{\circ} \mathbf{C}$ & $\mathbf{T}_{\mathbf{a}}=\mathbf{3 6}^{\circ} \mathbf{C}$ \\
\hline Toluene & 530 & 800 & 225 \\
\hline Benzene & 500 & 1150 & 225 \\
\hline Warfarin & 180 & 420 & 120 \\
\hline $\begin{array}{l}\text { methyl } \\
\text { alcohol }\end{array}$ & 1225 & 1800 & 800 \\
\hline ethyl alcohol & 1800 & 1225 & 800 \\
\hline $\begin{array}{l}2,4- \\
\text { dinitrophenol }\end{array}$ & 42 & 28 & 18 \\
\hline paraldehyde & 1500 & 2100 & 420 \\
\hline $\begin{array}{l}\text { carbon } \\
\text { tetrachloride }\end{array}$ & 1400 & 7100 & 940 \\
\hline DDT & 940 & 940 & 120 \\
\hline
\end{tabular}

Data taken from Keplinger et al. (50).

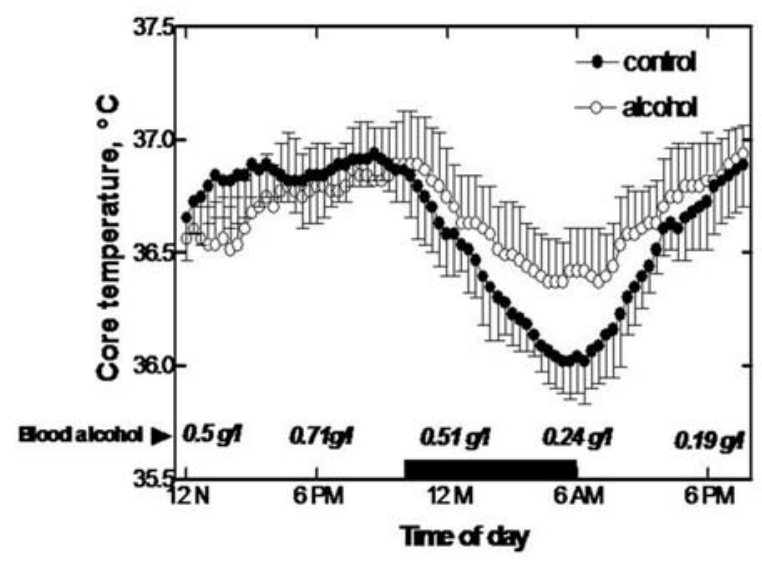

Figure 15. Circadian profile of core temperature of nine healthy men given a control fluid or $256 \mathrm{~g}$ of alcohol administered regularly over a 26-hour period. Note significant hyperthermic effect of ethanol only during the night. Also note transient hypothermia at start of alcohol exposure. Blood alcohol levels measured at selected hours is given in italics. Data modified from Danel et al. (62).

dosing at environmental temperatures of 8,26 , and $36{ }^{\circ} \mathrm{C}$ (Table 3). The lethal dose was consistently lower when administered to rats maintained at an ambient temperature of $36{ }^{\circ} \mathrm{C}$ as compared to a temperature of $26{ }^{\circ} \mathrm{C}$ (i.e., slightly below the rat's thermoneutral zone). It is interesting to note the consistent effect of higher environmental temperatures on chemical lethality in spite of marked differences in the chemical's mechanism of action. For example, in rats DDT causes tremor and hyperthermia and would be expected to be more toxic at higher temperatures by inducing hyperthermic death.

Lethality as an endpoint has fortunately been phased out in most toxicological research. However, the lethality data illustrates the ultimate impact of temperature on the sensitivity to a toxicant. Non-lethal endpoints have also been used in many studies to show the benefits of a moderate reduction in core temperature on the sensitivity to environmental toxicants. For example, plasma levels of enzymes that are indicators of liver function have been found to be affected by ambient and body temperature. Watanabe et al. (51) dosed mice with sodium selenite and maintained them at ambient temperatures of 9,22 , or $33^{\circ} \mathrm{C}$ for just $4.5 \mathrm{hr}$ ( $1.5 \mathrm{hr}$ before and $3 \mathrm{hr}$ after injection). After three days of recovery at an ambient temperature of $22{ }^{\circ} \mathrm{C}$, plasma levels of lactate dehydrogenase (LDH) were found to be markedly affected by the brief exposure to mild warm or cold stress (Figure 14). There are many other examples of non-lethal endpoints to toxicants that are modulated by temperature (see 1).

\section{DELAYED AND CHRONIC EFFECTS}

Radiotelemetric monitoring of undisturbed rodents has provided valuable information on the delayed effects as the thermoregulatory system recovers from a toxic insult. The psychological stress of repeated handling and insertion of colonic probes in rats and mice will obviate any subtle effects of a toxicant on thermoregulation. That is, it would be unlikely to detect a toxicant-induced fever in a rodent if the treated and control animals are repeatedly handled and have their colonic temperature measured with a conventional probe. Gallaher and Egner (52) first used radiotelemetry to document a delayed hyperthermic response in the rat as it recovered from acute ethanol exposure. Following recovery from the hypothermic effects of ethanol, there was a significant elevation in the daytime core temperature that persisted for up to 4 days after dosing with $6-8 \mathrm{~g} / \mathrm{kg}$. It is important to note that blood alcohol levels essentially recover to zero by 24 hours after dosing, well before the development of the hyperthermic response. A similar delayed elevation in core temperature is also seen in humans dosed with alcohol (Figure 15). However, it is important to note in comparison of the human and rat responses that the alcohol-induced rise in core temperature of humans occurs during the night when core temperature is normally decreasing, in humans.

Our laboratory first showed a similar fever response to an organophosphate, DFP (53). The acute hypothermic effects of DFP in rats and mice were well characterized (33). We found that, following recovery from hypothermia, the DFP-treated rat maintained an elevated core temperature during the day for at least 48 hours after exposure. This delayed elevation in body temperature has been shown in rats dosed with OP-based insecticides chlorpyrifos and diazinon, and carbaryl, a carbamate-based insecticide (54). As was shown in the ethanol study by Gallaher, the delayed elevation in core temperature following exposure to the anticholinesterase agents was manifested during the daytime of the rat's circadian rhythm, corresponding with the time when core temperature is normally at its lowest point (see Figure 8). This is a typical pattern in rodents subjected to infectious fevers (for discussion, see 1).

Viewing the time-course core temperature data in Figure 8, one could contend that the delayed rise in core temperature is a type of "rebound" or overcompensation as the animal recovers from a prolonged hypothermic state. However, there are several reasons to suggest that it is not a rebound. The elevation in temperature is manifested during the day but not during the night, suggesting that there is some form of regulation. Blocking the acute hypothermic 
Table 4. A list of drugs reported to cause immunemediated drug fever. From Cuddy (58). Partial list of drugs selected by this author based on their possible relevance to toxicant-induced hyperthermia

\begin{tabular}{|l|}
\hline Allopurinol \\
\hline Aminoglycosides \\
\hline Antihistamine \\
\hline Atropine \\
\hline Barbiturates \\
\hline Blood transfusions \\
\hline Corticosteroids \\
\hline Folate \\
\hline Haloperidol \\
\hline Heparin infusion \\
\hline Hydroxyurea \\
\hline Iodides \\
\hline IV immune globulin \\
\hline Methyldopa \\
\hline Nonsteroidal anti-inflammatory agents \\
\hline Para-aminosalicylic acid \\
\hline Phenytoin \\
\hline Propylthiouracil \\
\hline Quinidine \\
\hline Salicylates \\
\hline Streptomycin \\
\hline Sulfonamides \\
\hline Tetracylines \\
\hline Vitamin preparations \\
\hline
\end{tabular}

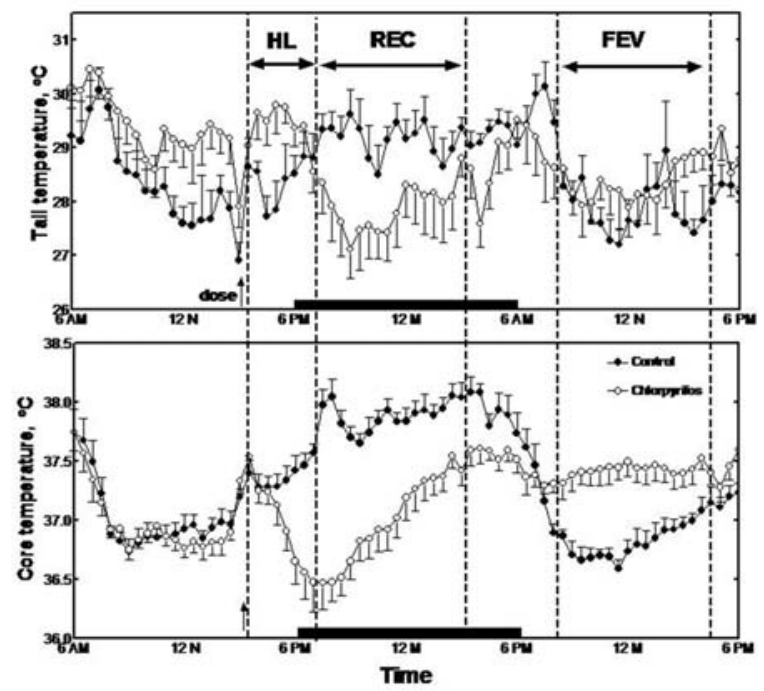

Figure 16. Time-course of tail skin temperature and core temperature in rats dosed orally with corn oil (control) or chlorpyrifos $(25 \mathrm{mg} / \mathrm{kg})$. Three phases are noted: HL-heat loss phase where tail skin temperature remains elevated as core temperature decreases; REC-recovery phase where there is a marked reduction in tail skin temperature concomitant with stabilization and gradual recovery of core temperature; and FEV or fever phase where core temperature is elevated above controls while tail skin temperature is similar to control levels. From Gordon et al. (62).

response to chlorpyrifos by maintaining the rats at thermoneutral ambient temperature did not block the delayed hyperthermic response (29). The rise in temperature from chlorpyrifos and diazinon is blocked by administration of an antipyretic, suggesting that the temperature rise is akin to a fever and is mediated by activation of the cyclo-oxygenase pathway $(54,55)$. Recording tail skin temperature as an indicator of tail blood flow in chronically instrumented rats showed an increase in heat loss at the onset of the development of hypothermia, a restriction in heat loss as the animals recovered from the acute hypothermia and no change in heat loss during the delayed fever (Figure 16). The lack of a heat dissipating response during the period of a delayed fever would suggest that the elevated temperature is regulated. Furthermore, rats allowed to behaviorally thermoregulate in a temperature gradient do not select cooler ambient temperatures during the delayed fever period. Again, this suggests that the thermoregulatory system is defending the elevated core temperature (29).

\section{SCALING THERMOREGULATORY RESPONSES TO TOXIC AGENTS}

It is important to consider the differences in body size, surface area:mass ratio, and metabolic rate when extrapolating toxicological effects from rodent to human. As discussed earlier for alcohol, the magnitude of the acute hypothermic response to toxicants and drugs that is observed in laboratory rodents is generally not seen in adult humans and other large mammals. In fact, a hyperthermic response is commonly seen in humans subjected to antiChE insecticides, metal fumes, and a variety of other toxicants $(1,56,57)$. The hyperthermic response may be regulated, being similar to a fever, or it may be a forced elevation in core temperature. Humans exposed acutely to organophosphate insecticides can exhibit an elevated temperature that persists for days, suggesting that it is regulated.

"Drug fever" is often reported in the clinical literature and refers to the various ways that many types of drugs that can lead to an increase in body temperature in humans (58). Indeed, there are numerous types of drugs and drug interactions that are reported to raise body temperature in humans; however, the mechanism of action (i.e., forced versus regulated hyperthermia) is only understood for some of the agents (Table 4). Drug fever is noted in this review because of the potential that the mechanism of action of some toxicants on temperature regulation in humans may be related to drug fever. There are few animal models that replicate the incidences of human drug fever.

Adult humans exposed to antiChE insecticides can display a moderate hypothermic response but this rarely reaches the magnitude of hypothermia seen is small rodents exposed acutely to these insults. As body size increases, the surface area: body mass ratio decreases, thus limiting the ability to dissipate heat and lower core temperature. For example, a 30 gram mouse has approximately 17 times the surface area: body mass ratio as compared to an adult $80 \mathrm{~kg}$ human. Hence, there are physical limitations to dissipate heat normalized per unit body weight with increasing body size. Rodents dissipate heat faster and have the ability to quickly lower core temperature in response to toxicant exposure. The thermal inertia of a large mammal such as a human impedes the 
ability to lower core temperature in a rapid manner. Rodents are considered metabolic specialists, meaning that their core temperature is intimately dependent on their metabolic heat production (59). They have the ability to abruptly increase or reduce metabolic heat production, leading to a rapid change in body temperature. Large mammals, such as humans, rely more on peripheral vasomotor tone to regulate core temperature. Abrupt, rodent-like changes in core temperature are not likely in large mammals.

It appears that rodent models of thermoregulation are reasonable predictors of human responses provided that the aforementioned issues are taken into consideration. In view of the temperature dependency of biochemical and physiological, scaling the thermoregulatory responses from rodent to human can be important in the extrapolation of a variety of toxicological responses that are not associated with thermoregulation. Adult humans and other relatively large species are essentially trapped in their stable thermal milieu and cannot respond with a natural hypothermic response when faced with a toxic insult (60). Since hypothermia is protective and rodents are able to use this as an adaptive mechanism to a toxic insult, this may lead to one to underestimate the risk of a toxicant when extrapolating from a small rodent to adult human.

\section{ACKNOWLEDGEMENTS}

I thank Drs. Amir Rezvani and William Boyes for their review of the manuscript. I also thank Britton Bishop for editing and proofing. This paper has been reviewed by the National Health and Environmental Effects Research Laboratory, U.S. Environmental Protection Agency, and approved for publication. Mention of trade names or commercial products does not constitute endorsement or recommendation for use.

\section{REFERENCES}

1. C. J. Gordon. Temperature and Toxicology: An Integrative, Comparative, and Environmental Approach. CRC Press, Boca Raton, FL. (2005)

2. IUPS Thermal Commission: Glossary of terms for thermal physiology. Third edition. Revised by The Commission for Thermal Physiology of the International Union of Physiological Sciences. Jap J Physiol 51, 245-280 (2001)

3. C. J. Gordon. Temperature Regulation in Laboratory Rodents. New York: Cambridge University Press. (1993)

4. S. Wood, W.N. Rom, White, G.L. and D. C. Logan: Pentachlorophenol poisoning. J Occ Med 25, 527-530 (1983)

5. A. R. Cossins and K. Bowler. Temperature Biology of Animals. Chapman and Hall: London. (1987)

6. B. E. Ballard: Pharmacokinetics and temperature. $J$ Pharm Sci 63, 1345-1358 (1974)
7. C. J. Gordon and L. Leon. Thermal stress and physiological response to environmental toxicants. Env. Hlth. Pers. 20, 235-263 (2005)

8. S.-K. Chang, and J. E. Riviere. Percutaneous absorption of parathion in vitro in porcine skin: Effects of dose, temperature, humidity, and perfusate composition on absorptive flux. Fund. Appl. Toxicol. 17: 494-504 (1991)

9. A. J. Funckes, G. R. Hayes, Jr., and W. V. Hartwell: Urinary excretion of paranitrophenol by volunteers following dermal exposure to parathion at different ambient temperatures. J. Agric. Food Chem. 11,455-457 (1963)

10. J. Vanakoski, T. Seppala, E. Sievi, and E. Lunell. Exposure to high ambient temperature increases absorption and plasma concentrations of transdermal nicotine. Clin. Pharmaco.l Ther. 60, 308-315 (1996)

11. S. M. Gordon, L. A. Wallace, P. J. Callahan, D. V. Kenny and M. C. Brinkman. Effect of water temperature on dermal exposure to chloroform. Env. Hlth. Pers. 106, 337$345(1998)$

12. W. J. Mautz. Exercising animal models in inhalation toxicology: interactions with ozone and formaldeyhyde. Environ. Res. 92, 14-26 (2003)

13. J. S. Sorenson, J. D. McLister and M. D. Dearing. Plant secondary metabolites compromise energy budgets of a specialist and generalist mammalian herbivore. Ecology 86, 125-139 (2005)

14. J. Doull. The effect of physical environmental factors on drug response. Essays in Toxicology 3, 37-63 (1972)

15. R. D. Malcolm and R. L. Alkana: Temperature dependence of ethanol lethality in mice. J. Pharm. Pharmacol. 35, 306-311 (1983)

16. M. Bejanian, D. A. Finn, P. J. Syapin and R. L. Alkana. Body temperature and ethanol pharmacokinetics in temperature-challenged mice. Alcohol 7, 331-337 (1990)

17. E. Romm and A. C. Collins. Body temperature influences on ethanol elimination rate. Alcohol 4, 189-198 (1987)

18. K. Nishida, M. Okazaki, R. Sakamoto, N. Inaoka, H. Miyake, S. Fumoto, J. Nakamura, M. Nakashima, H. Sasaki, M. Kakumoto and T. Sakaeda. Change in pharmacokinetics of model compounds with different elimination processes in rats during hypothermia. Biol. Pharm. Bull. 30:1763-67 (2007)

19. W. G. Clark and J. M. Lipton. Changes in body temperature after administration of amino acids, peptides, dopamine, neuroleptics and related agents: II. Neuroscience and Biobehav. Rev. 9, 299-371 (1985)

20. W. G. Clark and J. M. Lipton. Changes in body temperature after administration of acetylcholine, histamine, 
morphine, prostaglandins and related agents: II. Neurosci. Biobehav. Rev. 9, 479-552 (1985)

21. V. C. Moser. Comparisons of the acute effects of cholinesterase inhibitors using a neurobehavioral screening battery in rats. Neurotox. Terat. 17, 617-625 (1995)

22. P. Tamborini, H. Sigg and G. Zbinden. Acute toxicity testing in the nonlethal dose range: A new approach. Reg. Toxicol. Pharm. 12, 69-87 (1990)

23.C. J. Gordon, P. J. Spencer, J. Hotchkiss, D. B. Miller, P. M. Hinderliter and J. Pauluhn. Thermoregulation and its influence on toxicity assessment. Toxicology 244, 87-97 (2008)

24. C. J. Gordon. A review of terms and proposed nomenclature for regulated vs. forced changes in body temperature. Life Sci. 32, 1285-1295 (1983)

25. C. J. Gordon, F. S. Mohler, W. P. Watkinson and A. H. Rezvani. Temperature regulation in laboratory mammals following acute toxic insult. Toxicology 53, 161-178 (1988)

26. A. N. Taylor, H. E. Romeo, A. V. Beylin, D. L. Tio, S. U. Rahman and D. A. Hovda: Alcohol consumption in traumatic brain injury: Attenuation of TBI-induced hyperthermia and neurocognitive deficits. J. Neurotrauma 19, 1597-1608 (2002)

27. F. T. Caldwell, Jr., D. B. Graves and B. H. Wallace: Chronic indomethacin administration blocks increased body temperature after burn injury in rats. J. Burn Care Rehab. 19, 501-511 (1998)

28. W. G. Clark and J. M. Lipton: Complementary lowering of the behavioural and physiological thermoregulatory setpoints by tetrodotoxin and saxitoxin in the cat. J. Physiol. 238, 181-191 (1974)

29. C. J. Gordon. Behavioral thermoregulatory response to chlorpyrifos in the rat. Toxicology 124, 165-171.

30. Gordon, C.J. (1994a). 24-hour control of body temperature in the rat: II. Diisopropyl fluorophosphate-induced hypothermia and hyperthermia. Pharmacol. Toxicol. Behav. 49, 747-754 (1997)

31. C. Watanabe Suzzuki. Sodium selenite-induced hypothermia in mice: indirect evidence for a neural effect. Toxicol. Appl. Pharmacol. 86: 372-379 (1986)

32. L. R. Leon. Thermoregulatory responses to environmental toxicants: The interaction of thermal stress and toxicant exposure. Toxicol. Appl. Pharmacol. 233, 146-161 (2008)

33. C. J. Gordon. Thermoregulation in laboratory mammals and humans exposed to anticholinesterase agents. Neurotox. Terat. 16, 427-453 (1994)

34. C. J. Gordon and T. A. Grantham. Effect of central and peripheral cholinergic antagonists on chlorpyrifos-induced changes in body temperature in the rat. Toxicology 142, 1528 (1999)

35. R. P. Maickel, D. R. Kinney and M. B. Nichols. Antagonism of physostigmine induced hypothermia and neuroendocrine changes following exposure to different environmental temperatures. Prog. Neuropsychopharm. Biol. Psych. 15, 873-884 (1991)

36. H. Kalent and A. D. Le. Effects of ethanol on thermoregulation. Pharmacol. Therap. 23, 313-364 (1984)

37. R. D. Myers. Alcohol's effect on body temperature: hypothermia, hyperthermia, or poikilothermia. Brain Res. Bull. 7, 209-220 (1981)

38. C. J. Gordon and A.G. Stead. Effect of acute ethanol treatment on behavioral and autonomic thermoregulation in mice. Alcohol 3, 339-343 (1986)

39. C. J. Gordon, L. Fogelson, F. Mohler, A. Stead and A. Rezvani. Behavioral thermoregulation in the rat following the oral administration of ethyl alcohol. Alcohol Alcoholism 23, 383-390 (1988)

40. C. S. O'Connor, L. I. Crawshaw, A. Kosobud, R. C. Bedichek and J. C. Crabbe. The effect of ethanol on behavioral temperature regulation in mice. Pharmacol. Biochem. Behav. 33, 315-319 (1989)

41. E. Briese and L. Hernandez. Ethanol anapyrexia in rats. Pharmacol. Biochem. Behav. 54, 399-402 (1996)

42. P. Lomax, J. B. Bajorek, W. A. Chesarek and R. R. Chaffee. Ethanol-induced hypothermia in the rar. Pharmacology 21, 288-294 (1980)

43. T. Yoda, L. I. Crawshaw, M. Nakamura, K. Saito, A. Konishi, K. Nagashima, S. Uchida and K. Kanosue. Effects of alcohol on thermoregulation during mild heat exposure in humans. Alcohol 36, 195-200 (2005)

44. T. Yoda, L.I. Crawshaw, K. Saito, M. Nakamura, A. Konishi, K. Nagashima and K. Kanosue. Effects of alcohol on autonomic responses and thermal sensation during cold exposure in humans. Alcohol 42, 207-212(2008)

45. P. M. Hudson, P. H. Chen, H. A. Tilson and J. S. Hong: Effects of $p, p$ '-DDT on the rat brain concentrations of biogenic amine and amino acid neurotransmitters and their association with $p, p^{\prime}$-DDT-induced tremor and hyperthermia. J. Neurochem. 45, 1349-1355 (1985)

46. D. E. Woolley: Studies on 1,1,1-trichloro-2,2bis (pchlorophenyl) ethane (DDT)-induced hyperthermia: effects of cold exposure and aminopyramine injections. $J$. Pharmaco.l Exp. The.r 184, 261-268 (1973)

47. T. N. Takehiro, K. Shida Y. C. and Lin: Effects of 2,4dinitrophenol on the body temperature cardiopulmonary functions in unanesthetized rats, Rattus rattus. $J$ Thermal Biol 4, 297-301 (1979) 
48. D. E. Ray and J. R. Fry. A reassessment of the neurotoxicity of pyrethroid insecticides. Pharmacol. Therap. 111, 174-193 (2006)

49. F. A. Fuhrman. The effect of body temperature on drug action. Physiol. Rev. 26, 247-274 (1946)

50. M. L. Keplinger, G. E. Lanier and W. B. Deichmann. Effects of environmental temperature on the acute toxicity of a number of compounds in rats. Toxicol. Appl. Pharmacol. 1, 156-161 (1959)

51. C. Watanabe, T. Suzuke and N. Matsuo. Toxicity modification of sodium selenite by a brief exposure to heat or cold in mice. Toxicology 64: 245-253 (1990)

52. E. J. Gallaher and D. A. Egner. Rebound hyperthermia follows ethanol-induced hypothermia in rats. Psychopharmacology 91, 34-39 (1987)

53. C. J. Gordon: Acute and delayed effects of diisopropyl fluorophosphate on body temperature, heart rate, and motor activity in the awake, unrestrained rat. J. Toxicol. Environ. Hlth. 39, 247-260 (1993)

54. C. J. Gordon and C. M. Mack Influence of gender on thermoregulation and cholinesterase inhibition in the Long-Evans rat exposed to diazinon. J. Toxicol. Environl Hlth A. 66, 291-304 (2003)

55. C. J. Gordon, T. A. Grantham and Y. Yang. Hypothermia and delayed fever in the male and female rat exposed to chlorpyrifos. Toxicology 118, 149-158 (1997)

56. A. M. Saadeh, M. K. Al-Ali, N. A. Farsakh and M. A. Ghani. Clinical and sociodemographic features of acute carbamate and organophosphate poisoning: A study of 70 adult patients in North Jordan. Clin. Toxicol. 34, 45-51 (1996)

57. T. Namba, C. T. Nolte, J. Jackrel and G. Grob: Poisoning due to organophosphate insecticides. Am. J. Med. $50,475-492(1971)$

58. M. L. S. Cuddy, M.L.S. The effects of drugs on thermoregulation. AACN Clin. Issues 15, 238-253 (2004)

59. P. K. Phillips and J. E. Heath: Dependency of surface temperature regulation on body size in terrestrial mammals. J. Thermal Biol. 20: 281-289 (1995)

60. C. J. Gordon: Homeothermy: Does it impede the response to cellular injury. J. Thermal Biol. 21:29-36 (1996)

61. M. Wolansky, K. Crofton and C. J. Gordon. Effect of pyrethroids on body temperature in rats. Society of Toxicology, Charlotte, NC. (2007)

62. T. Danel, C. Libersa and Y. Touitou: The effect of alcohol consumption on the circadian control of human core body temperature is time dependent. Am. J. Physiol. 281: R52-R55 (2001)

63. C. J. Gordon, E. Puckett and B. Padnos: Rat tail skin temperature monitored non-invasively by radiotelemetry: characterization by examination of vasomotor response with thermomodulatory agents. J. Pharmacol. Toxicol. Meth. 47: 107-114 (2002)

64. Y. Yang, and C.J. Gordon: Ambient temperature limits and stability of temperature regulation in telemetered male and female rats. J. Thermal Biol. 21: 353-363 (1996)

65. A.A. Romanovsky, O. Shido, S. Sakurada, N. Sugimoto, and T. Nagasaka (1996). Endotoxin shock: thermoregulatory mechanisms. Am. J. Physiol. 270: R693R703 (1996)

Key Words: Core Temperature, Environmental Toxicants, Skin Temperature, Sweating, Metabolism, Heat Stress, Review

Send correspondence to: Christopher J. Gordon, Christopher J. Gordon, B105-04, NTD, NHEERL, U.S. EPA, RTP, NC 27711, Tel: 919 541-1509, Fax: 919 5414416, E-mail: gordon.christopher@epa.gov

http://www.bioscience.org/current/vol2E.htm 